Article

\title{
Potential of AOD Retrieval Using Atmospheric Emitted Radiance Interferometer (AERI)
}

\author{
Jongjin Seo ${ }^{1,2,+}$, Haklim Choi $^{3, *,+}\left(\mathbb{C}\right.$ and Youngsuk $\mathrm{Oh}^{4}[\mathbb{C}$ \\ 1 Department of Atmospheric and Oceanic Sciences, University of Wisconsin-Madison, \\ Madison, WI 53706, USA; jseo47@wisc.edu \\ 2 Space Science and Engineering Center, University of Wisconsin-Madison, Madison, WI 53706, USA \\ 3 Kyungpook Institute of Oceanography, Kyungpook National University, Daegu 41566, Korea \\ 4 Innovative Meteorological Research Department, National Institute of Meteorological Sciences, \\ Seogwipo-si 63568, Korea; ysoh306@korea.kr \\ * Correspondence: haklim84@knu.ac.kr \\ + These authors contributed equally to this work.
}

Citation: Seo, J.; Choi, H.; Oh, Y. Potential of AOD Retrieval Using Atmospheric Emitted Radiance Interferometer (AERI). Remote Sens. 2022, 14, 407. https://doi.org/ $10.3390 /$ rs 14020407

Academic Editor: Chang-Keun Song

Received: 25 November 2021

Accepted: 13 January 2022

Published: 16 January 2022

Publisher's Note: MDPI stays neutral with regard to jurisdictional claims in published maps and institutional affiliations.

Copyright: (C) 2022 by the authors. Licensee MDPI, Basel, Switzerland. This article is an open access article distributed under the terms and conditions of the Creative Commons Attribution (CC BY) license (https:// creativecommons.org/licenses/by/ $4.0 /)$.

\begin{abstract}
Aerosols in the atmosphere play an essential role in the radiative transfer process due to their scattering, absorption, and emission. Moreover, they interrupt the retrieval of atmospheric properties from ground-based and satellite remote sensing. Thus, accurate aerosol information needs to be obtained. Herein, we developed an optimal-estimation-based aerosol optical depth (AOD) retrieval algorithm using the hyperspectral infrared downwelling emitted radiance of the Atmospheric Emitted Radiance Interferometer (AERI). The proposed algorithm is based on the phenomena that the thermal infrared radiance measured by a ground-based remote sensor is sensitive to the thermodynamic profile and degree of the turbid aerosol in the atmosphere. To assess the performance of algorithm, AERI observations, measured throughout the day on 21 October 2010 at Anmyeon, South Korea, were used. The derived thermodynamic profiles and AODs were compared with those of the European center for a reanalysis of medium-range weather forecasts version 5 and global atmosphere watch precision-filter radiometer (GAW-PFR), respectively. The radiances simulated with aerosol information were more suitable for the AERI-observed radiance than those without aerosol (i.e., clear sky). The temporal variation trend of the retrieved AOD matched that of GAW-PFR well, although small discrepancies were present at high aerosol concentrations. This provides a potential possibility for the retrieval of nighttime AOD.
\end{abstract}

Keywords: retrieval algorithm; AOD; AERI; hyper-spectral; infrared; optimal estimation method

\section{Introduction}

Aerosols suspended in the atmosphere play an essential role in regional weather and global climate change as they both directly and indirectly affect radiative forcing due to the scattering, absorption, and transmittance in the radiative transfer process [1-3]. Moreover, the presence of aerosols in the atmosphere affects polarization and the amount of radiation observed from ground-based observations as well as satellites [4], so it affects the retrieval performance of atmospheric composition from remote-sensing instruments. Therefore, various studies have improved the accuracy of the retrieved atmospheric information by considering the aerosol information [5-7]. Additionally, Lee [8] noted the importance of aerosol observations with known uncertainties in the regional grid to improve the radiative forcing for aerosols and model prediction. Thus, accurate and abundant information needs to be obtained on aerosols.

Generalizing the physical and optical properties of aerosols, such as the particle size distribution and refractive indices, is difficult because of the high variabilities including the source of formation, diverse compositions, and aging of the aerosol particles as well as interaction with the atmospheric states. Therefore, many aerosol models characterize 
the physical and optical properties of aerosols into the representative aerosol types and their mineral and chemical compositions using in situ measurements and remote sensing observations [9-12]. To characterize the various aerosol optical and physical properties, aerosol optical depth (AOD) is an essential parameter representing the extinction of the light by aerosols in an atmospheric column because AOD is determined using both physical and optical properties of aerosol compositions; thus, long-term AOD observations represent inherent aerosol characteristics, including the seasonality and different sources at a geophysical location [13]. Consequently, numerous studies have been conducted to observe the climatological AOD through remote sensing techniques using satellite [14] and ground-based measurements [13] as well as using both remote sensing observations [15].

Advantageously, satellite remote sensing can monitor the global coverage, including regions in which ground-based observations are difficult. Recently, plenty of well-established aerosol observations have been obtained from satellites. For example, the moderate resolution imaging spectroradiometer (MODIS) onboard the Aqua and Terra satellites provides the AOD retrieved using the radiance from seven spectral channels between 470 and $2130 \mathrm{~nm}[16,17]$. The ozone monitoring instrument (OMI) onboard the Aura satellite provides the retrieved $A O D$ and vertical distribution as well as a single scattering albedo via the OMI near-ultraviolet aerosol retrieval algorithm (OMAERUV) $[18,19]$. However, these polar-orbiting satellites find it hard to capture the diurnal variations in AOD due to the temporal resolution from 1 to 2 days and the global coverage.

Ground-based remote sensing instruments have higher temporal resolutions than satellites, which advantageously enable the continuous aerosol changes in the atmosphere at a certain location to be monitored. The aerosol robotic network (AERONET), an automatic tracking sun- and sky-scanning radiometer, observes the AOD from sunlight in an visible region and derives the physical and optical characteristics of the aerosol such as size distribution, refractive indices, and single scattering albedo [13]. Furthermore, due to the high accuracy and global network $[20,21]$, AERONET was widely used as a representative ground-based measurement for comparison with satellite measurements [22] to improve the accuracy of the AOD retrieval algorithm [23] and to generate the climatological aerosol model [13]. However, since the visible spectral region was used to obtain the aerosol data, AERONET was only operated in the daytime and AOD information is limited during the nighttime. Additionally, Zhang [24] showed that the radiative impacts of aerosols are not negligible during nighttime and showed the asymmetric changes in radiative forcing from the daytime using the Weather Research and Forecasting model coupled with chemistry (WRF-Chem). Therefore, the continuous retrieval of AOD at nighttime using ground-based instrument needs to be investigated.

Nighttime atmospheric information can be obtained from the infrared radiance spectrum. The atmospheric emitted radiance interferometer (AERI) $[25,26]$, which is a Fourier transform infrared (FTIR), is a commercially available, ground-based spectrometer. It measures the hyperspectral, downwelling radiation emitted in IR regions so that it can operate in the daytime as well as the nighttime. AERI was used in a wide range of atmospheric research, including for the verification of the infrared radiative transfer models [27], retrieval of trace gases [28], long-term climate trend analyses [29], and the retrieval of thermodynamic profiles [30,31]. Moreover, Turner [32] retrieved physical and optical properties for the dust type above the Sahel via AERI observation using sonde and microwave radiometer (MWR) data.

Herein, we investigate the possibility of AOD retrieval using hyperspectral infrared radiance measured using AERI based on the optimal estimation method (OEM) and generalized the optical and physical properties of the aerosol model. Section 2 presents the observation site and instrumental characteristics of AERI as well as the global atmosphere watch precision-filter radiometer (GAW-PFR). Section 3 provides a detailed description of the algorithm with the OEM and radiative transfer model. Section 4 evaluates the retrieved thermodynamic profiles and AOD from the actual AERI observations in comparison with those from the ERA-5 and GAW-PFR in addition to the sensitivity analysis of downwelling 
emitted radiance within the AERI spectral regions. A discussion and the conclusions are presented in Sections 5 and 6, respectively.

\section{Instrumentations}

The Anmyeon observation site (AMY; $36.53^{\circ} \mathrm{N}, 126.32^{\circ} \mathrm{E}$ ) on the western coast of the Korean Peninsula is optimized to monitor the climate change and air pollution due to its advantageous geological location (Figure 1). Due to the prevailing westerlies, anthropogenic and natural continental pollutants usually inflow from eastern China, where metropolis and industries are located. Additionally, AMY is affected by a maritime aerosol such as sea salt driven from West Sea. Thus, the Korean Meteorological Administration (KMA) deployed the AERI to the Korea global atmosphere watch observatory (KGAWO) at AMY as part of the global atmosphere watch (GAW) program to observe the vertical structures of temperature and water vapor as well as the atmospheric concentrations of greenhouse gases such as $\mathrm{CH}_{4}, \mathrm{CO}$, and $\mathrm{CO}_{2}$ [33-35].

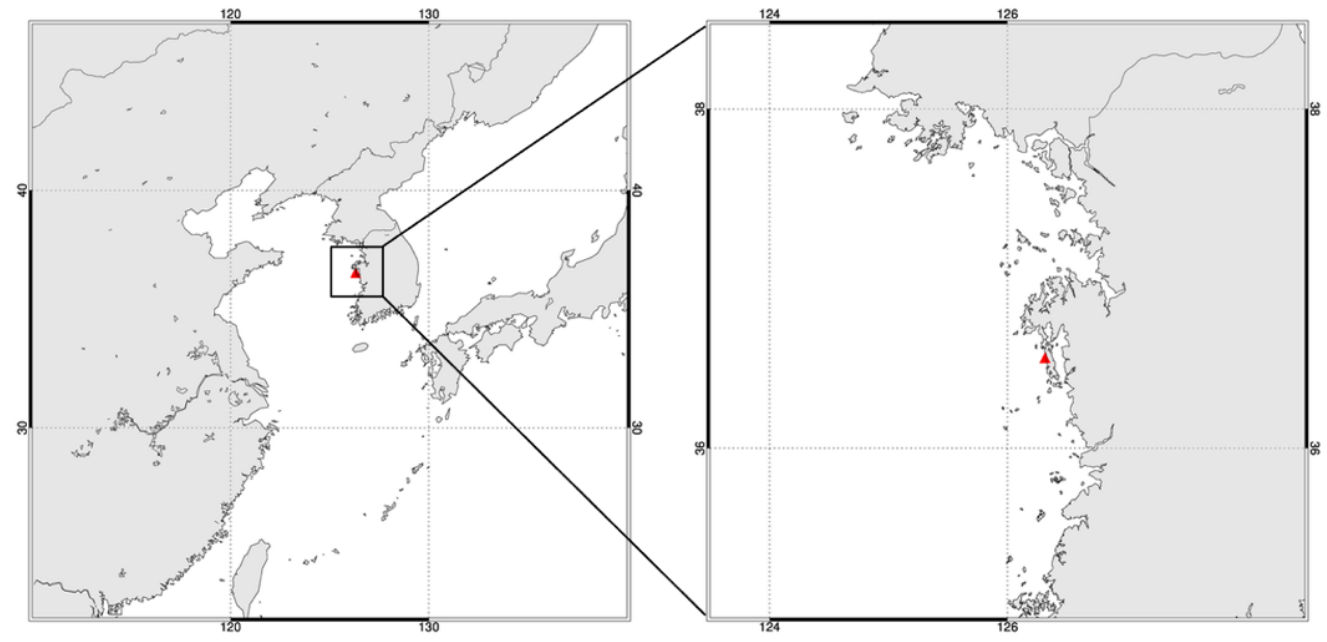

Figure 1. The location of Anmyeondo station (AMY, $36.53^{\circ} \mathrm{N}, 126.32^{\circ} \mathrm{E}$ ), South Korea (represented as a red triangle), where Atmospheric Emitted Radiance Interferometer (AERI) was installed.

\subsection{Atmospheric Emitted Radiance Interferometer}

AERI was developed for the U.S. department of energy's atmospheric radiation measurement (ARM) program by the University of Wisconsin-Madison space science and engineering center (SSEC). AERI measures the down-welling infrared radiance emitted from 550 to $3000 \mathrm{~cm}^{-1}(3.3-18.2 \mu \mathrm{m})$ with an unapodized spectral resolution of $0.5 \mathrm{~cm}^{-1}$ [25]. In addition to the atmospheric window $\left(800-1250 \mathrm{~cm}^{-1}\right)$, the AERI spectral range covers the various absorption bands of gases in the atmosphere, including water vapor $\left(\mathrm{H}_{2} \mathrm{O} ; 538-588\right.$ and $\left.1250-1350 \mathrm{~cm}^{-1}\right)$, carbon dioxide $\left(\mathrm{CO}_{2} ; 612-618,624-660,674-713\right.$, and 2223-2260 $\left.\mathrm{cm}^{-1}\right)$, ozone $\left(\mathrm{O}_{3} ; 980-1080 \mathrm{~cm}^{-1}\right)$, methane $\left(\mathrm{CH}_{4} ; 1150-1229 \mathrm{~cm}^{-1}\right)$, and carbon monoxide $(\mathrm{CO}$; $\left.2000-2200 \mathrm{~cm}^{-1}\right)$. Furthermore, the radiometric precision is accurately calibrated within $1 \%$ of the ambient radiance $(3 \sigma)$ with two onboard blackbodies (one at ambient air temperature and the other at $60{ }^{\circ} \mathrm{C}$ ) [26], and the temporal resolution used in this study is approximately $10 \mathrm{~min}$. Note that AERI is primarily operated automatedly and continuously over the diurnal cycle for a period of months and years. However, the AERI deployed in AMY was only observed on clear days and operated human-sources. Thus, the limited data, measured continuously during the day in 2010, were used to evaluate our proposed algorithm.

\subsection{Global Atmosphere Watch Precision-Filter Radiometer}

The GAW-PFR is a ground-based global and regional network of sun-photometers that was developed by the World Optical Depth Research and Calibration Center (WORCC) to observe the AOD and was designed to be continuous and operational under diverse weather conditions and long-term stable measurements. Additionally, GAW-PFR observes 
direct solar radiation at four independent wavelength channels $(368,412,500$, and $862 \mathrm{~nm})$ with a full width at half maximum (FWHM) of $5 \mathrm{~nm}$. The expected measured uncertainty of AOD in the four channels ranges from 0.004 at $862 \mathrm{~nm}$ to 0.01 at $368 \mathrm{~nm}$ [36].

The World Meteorological Organization (WMO, Genève, Switzerland) has operated the GAW-PFR as the reference instrument for long-term AOD observations, and various studies have compared the AOD observations from GAW-PFR and other networks, such as AERONET [37], the National Oceanic and Atmospheric Administration/Earth System Research Laboratory's (NOAA/ESRL) Surface Radiation Budget Observing Network (SURFRAD) [38], and Sky Radiometer Network (SKYNET) [39]. The AOD observations of GAW-PFR agree with those of AERONET for the 2005-2015 period, stating that the percentage of traceable data is higher than $92 \%$ for all wavelengths [37]. Herein, we utilized the GAW-PFR observations deployed with the AERI to evaluate our proposed AOD retrieval algorithm during the daytime. Note that the AERONET was also installed in AMY; unfortunately, the data for the study period are missing.

\section{Methodology}

The retrieval algorithm used to obtain AOD from AERI observations, named the AOD retrieval algorithm from AERI using the OEM (ARAOE), comprises two steps: (i) retrieve the vertical structure of temperature and water-vapor mixing ratio, and (ii) retrieve AOD based on the OEM using the radiative transfer model. Figure 2 illustrates the schematic flow of the algorithm.

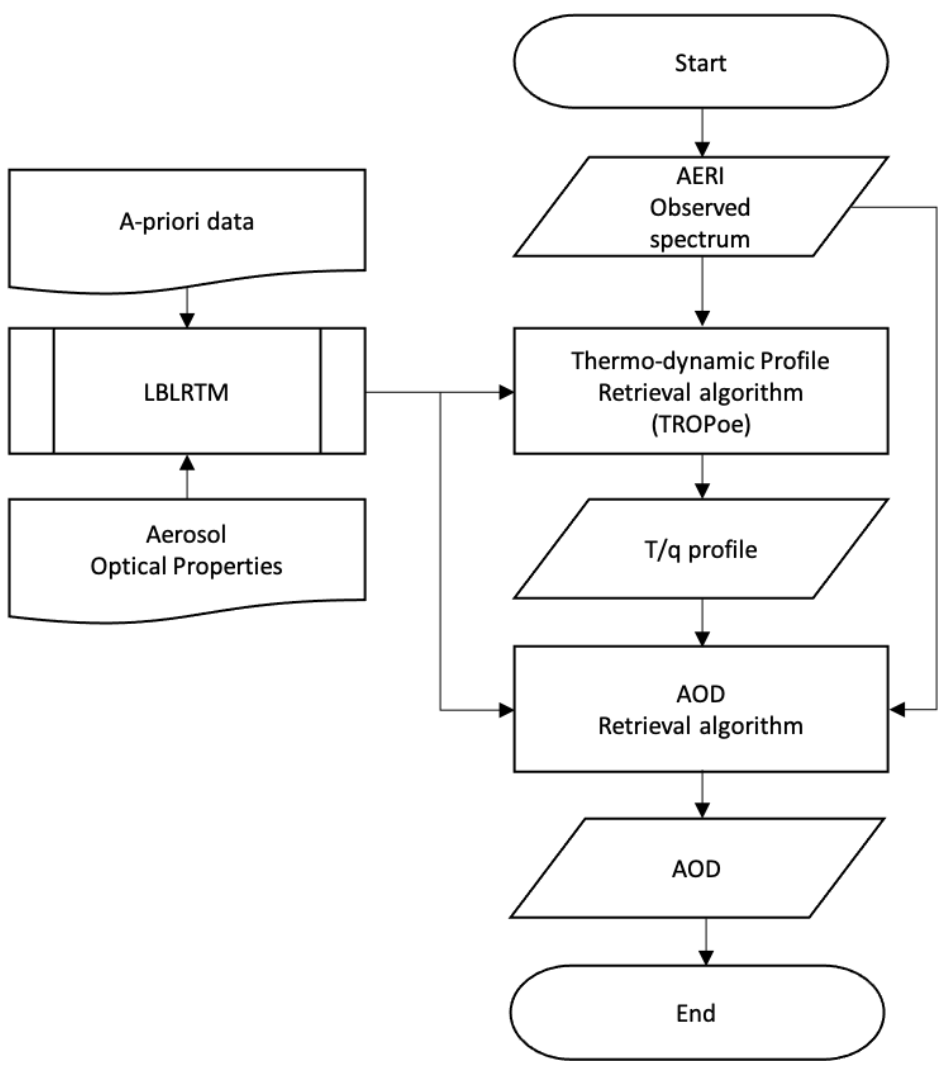

Figure 2. Flowchart of the ARAOE for retrieving the vertical structure of temperature and watervapor mixing ratio, and AOD.

To retrieve thermodynamic profiles, the Tropospheric Optimal Estimation Retrieval (TROPoe) algorithm $[30,31]$ was employed; it is a modern physical retrieval algorithm based on the OEM. TROPoe was designed to be relatively insensitive to the first-guess values, with two physical constraints: the derived relative humidity must be less than $100 \%$, and the potential temperature must monotonically increase with height [31]. Then, 
the radiative transfer model coupled with the aerosol model was iteratively employed to estimate AOD based on OEM, wherein the error between the observed radiance from AERI and the simulated radiance at the selected spectral regions was minimized.

\subsection{Radiative Transfer Model}

We used the LBLDIS radiative transfer model developed by [40], which combined the spectral gas optical depths computed by Line-By-Line Radiative Transfer Model (LBLRTM) [41,42] and aerosol effects from Discrete Ordinates Radiative Transfer (DISORT) $[43,44]$. Considering the contribution of the nearby absorption lines, LBLRTM calculates the optical depth of each atmosphere layer at a certain wavenumber. The monochromatic optical depth at a certain wavenumber for a vertical path $(\Delta z)$ was given as

$$
\tau_{\mathrm{v}}=\Delta \mathrm{z} \times\left[\sum_{\mathrm{i}}\left\{\sum_{\mathrm{j}} \mathrm{S}_{\mathrm{ij}} \mathrm{f}\left(\mathrm{v}-\mathrm{v}_{\mathrm{ij}}^{0}\right)\right\} \mathrm{n}_{\mathrm{i}}+\sigma_{\mathrm{v}}^{\mathrm{cont}} \mathrm{n}_{\mathrm{cont}}\right]
$$

where $S_{i j}$ is the line intensity of the ith line of the jth atmospheric species, $f\left(v-v_{i j}^{0}\right)$ is the line broadening located at $\mathrm{v}_{\mathrm{ij}}^{0}, \mathrm{n}_{\mathrm{i}}$ is the number density of ith species, and $\sigma_{\mathrm{v}}^{\text {cont }} \mathrm{n}_{\text {cont }}$ is the contribution of the continuum spectra. In LBLRTM, the optical properties of gases were acquired from the high-resolution transmission molecular absorption database (HITRAN) 2012 [45], and MlawerTobinCloughKneizysDavies (MT_CKD) v3.2 was used to consider the water-vapor continuum [46]. The spectral absorption line broadening was applied as the Voight profile [47]. The vertical grids of the atmosphere were set to 55 layers from the surface to $17 \mathrm{~km}$, and the vertical resolution was exponentially decreased from $25 \mathrm{~m}$ at the surface to $800 \mathrm{~m}$ at $3 \mathrm{~km}$.

To obtain the physical and optical properties of aerosol, the aerosol information was adopted from the database of Optical Properties of Aerosols and Clouds (OPAC), which contains various aerosol types [9]. Herein, we used three aerosol types for the simulation study - continental average (CA), maritime clean (MC), and urban (UR) aerosols-to consider the geolocational characteristics of the AMY observation site. The composition and physical characteristics of these aerosol types are presented in Table 1 . The aerosol types we used were composed of several single compositional particles. The water-soluble particles (WASO) were usual soil particles with some organic material. The water-insoluble particles (INSO) were the particles originating during gas-to-particle conversion and comprise various kinds of sulfates, nitrates, etc. Soot (SOOT) denotes the absorbing black carbon. CA and UR differ only in the number mixing ratio according to the degree of anthropogenic influence and have the same aerosol composition. MC mainly comprises sea salt; thus, it has larger-sized particles than the other aerosol types.

Table 1. Aerosol microphysical properties and height information for the mixture aerosol types from OPAC database.

\begin{tabular}{ccccccccc}
\hline Aerosol Type & Components & $\mathbf{r}_{\text {mod }}$ & $\mathbf{r}_{\text {min }}$ & $\mathbf{r}_{\text {max }}$ & $\boldsymbol{\sigma}$ & $\mathbf{N}_{\mathbf{i}}$ & $\mathbf{n}_{\mathbf{i}}$ & $\mathbf{Z}(\mathbf{k m})$ \\
\hline \multirow{2}{*}{ Continental Averaged } & WASO & 0.0212 & 0.005 & 20.0 & 2.24 & 7000 & 0.458 & $0.261 \times 10^{-4}$ \\
(CA) & INSO & 0.471 & 0.005 & 20.0 & 2.51 & 0.4 & 0.542 & 0.177 \\
& SOOT & 0.0118 & 0.005 & 20.0 & 2.00 & 8300 & $0.949 \times 10^{-5}$ & 8 \\
Urban & WASO & 0.0212 & 0.005 & 20.0 & 2.24 & 28,000 & 0.823 & 0.987 \\
(UR) & INSO & 0.471 & 0.005 & 20.0 & 2.51 & 1.5 & 130,000 & $0.132 \times 10^{-7}$ \\
Maritime Clean & SOOT & 0.0118 & 0.005 & 20.0 & 2.00 & 1 & 1 \\
(MC) & WASO & 0.0212 & 0.005 & 20.0 & 2.24 & 1500 & 20 & $0.211 \times 10^{-5}$
\end{tabular}

Note: WASO, INSO, SOOT, SSAM, and SSCM indicate the soluble, insoluble, soot, sea salt accumulated mode, and sea salt coarse mode, respectively. $r_{\text {mod }}$ and $\sigma$ are the parameters of lognormal size distribution, $N_{i}$ is the total particle number density per cubic centimeter, and $n_{i}$ is the number mixing ratio. $\mathrm{H}$ and $\mathrm{Z}$ are the thickness of the aerosol layer and aerosol scale height, respectively. 
The vertical distribution of aerosol particles is determined exponentially as follows:

$$
\mathrm{N}_{\mathrm{h}}=\mathrm{N}_{0} \mathrm{e}^{-\frac{\mathrm{h}}{\mathrm{Z}}}
$$

where $\mathrm{N}_{0}$ is the number density of the aerosol components at sea level, $\mathrm{h}$ is the altitude above a ground level, and $\mathrm{Z}$ is the scale height at $8 \mathrm{~km}(\mathrm{Z})$ for $\mathrm{CA}$ and UR and at $1 \mathrm{~km}$ for $\mathrm{MC}$ in the OPAC database,. The aerosol particles typically exit below $2-4 \mathrm{~km}$ in East Asia Region [48], so we assumed that the components of aerosol types were only loaded from the surface to $2 \mathrm{~km}$. The lognormal distribution [49] was applied for each compositional aerosol as follows (shown in Figure 3):

$$
\frac{\mathrm{dN}_{\mathrm{i}}(\mathrm{r})}{\mathrm{dr}}=\frac{\mathrm{N}_{\mathrm{i}}}{\sqrt{2 \pi \mathrm{r}} \log \sigma_{\mathrm{i}} \ln 10} \exp \left[-\frac{1}{2}\left(\frac{\log \left(\frac{\mathrm{r}}{\mathrm{r}_{\bmod \mathrm{N}, \mathrm{i}}}\right)}{\log \sigma_{\mathrm{i}}}\right)^{2}\right]
$$

where $r_{\bmod N, i}$ is the mode radius, $\sigma_{i}$ is the width of the distribution, and $N_{i}$ is the total particle number density of the component $i$ in particles per cubic centimeter. In the prospect of scattering, the size parameter $(x=2 \pi \mathrm{r} / \lambda)$ determines the scattering regimes between Rayleigh and Mie. The Rayleigh scattering regime, where the size parameter is smaller than $1(x \ll 1)$, is negligible in the thermal infrared, which is primarily sensitive to the high particle size of the aerosols, as indicated by the $8.0 \mu \mathrm{m}$ bar in Figure 3. Therefore, the emission contribution of SOOT to the downwelling radiance is very small and the emission contributions of INSO and sea salt aerosol are higher than the other compositional aerosols.

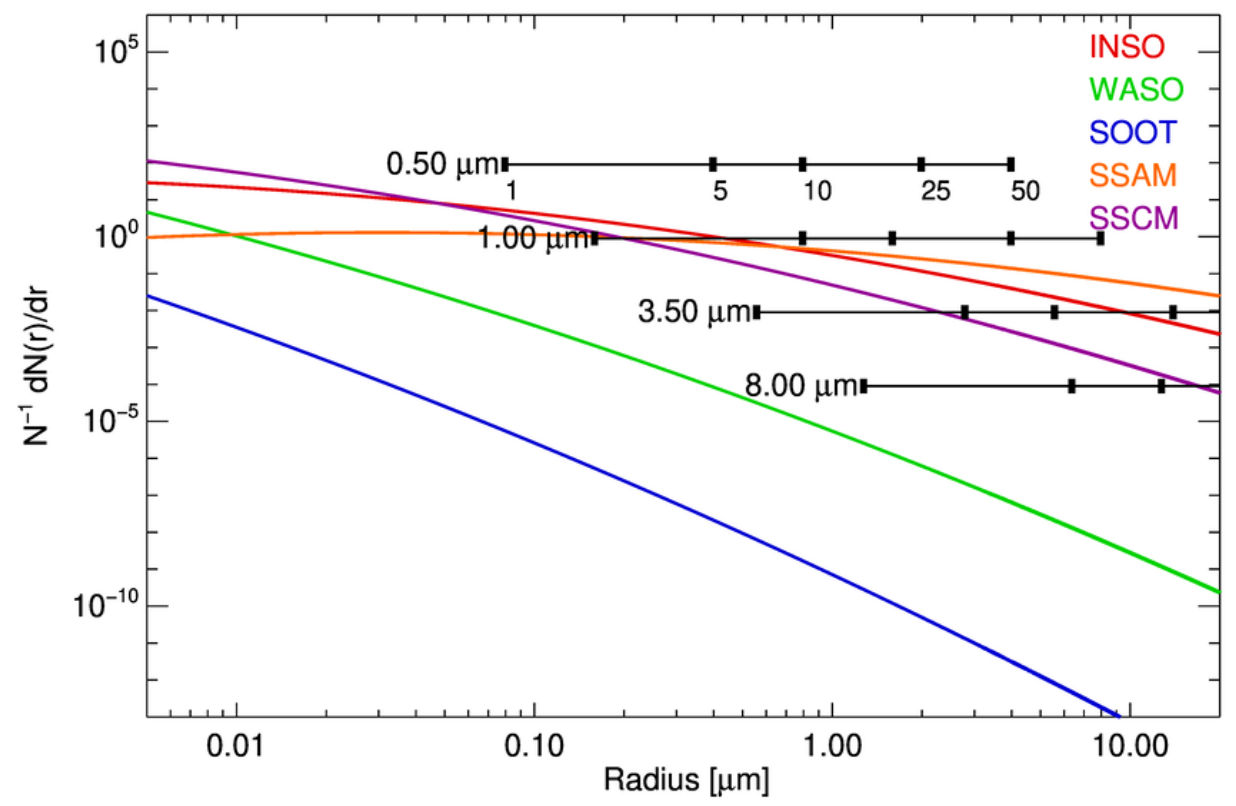

Figure 3. Lognormal size distribution of compositional aerosols, INSO (red), WASO (green), SOOT (blue), SSAM (orange), and SSCM (purple). The size parameters $(\chi=2 \pi r / \lambda)$ for various wavelengths $(0.5,1.0,3.5$, and $8.0 \mu \mathrm{m})$ are indicated as the black horizontal bars.

Since the AOD is determined by physical characteristics as well as refractive indices (Figure S1) that vary by wavelength, it needs to match the wavelengths between two AOD products: one is the observed value from GAW-PFR in the VIS regions and the other is the estimated value from the retrieval algorithm using the AERI-observed radiance in the IR regions. Two methods can be simply used to convert the spectral AOD value into a different wavelength: (i) using the Angstrom exponent value, which is a parameter that describes how the AOD typically depends on the wavelength [50], and (ii) calculating AOD using a radiative transfer model with the physical and optical properties of aerosol [9]. Herein, we 
decided to calculate the AOD at $500 \mathrm{~nm}$ using LBLDIS and aerosol information retrieved from our algorithm and compare it with the AOD observed from GAW-PFR. To acquire the spectral AOD that corresponds to $500 \mathrm{~nm}$, physical and optical information about the aerosol is required. Among the physical properties of aerosol, the size distributions and number mixing ratios of each aerosol type are not changed, but the number concentrations are obtained from the retrieval algorithm using AERI-observed radiance with OEM. Finally, a spectral AOD at $500 \mathrm{~nm}$ can be acquired by LBLDIS using the aerosol information from algorithm and the optical and physical aerosol properties in the VIS regions from OPAC database. Hereafter, AOD indicates spectral AOD at $500 \mathrm{~nm}$ in this study.

\subsection{Optimal Estimation Method}

To retrieve the thermodynamic profiles and AOD from the AERI-observed radiance, OEM, based on the Levenberg-Marquardt equation, was applied. This OEM combines the Gradient Descent and the Gauss-Newton methods to find the best solution. The state vector $\left(X^{n+1}\right)$, which is the vertical structure of temperature and the water-vapor mixing ratio in TROPoe and AOD in ARAOE, can be calculated as follows:

$$
X^{n+1}=X^{n}+\left[(1+\gamma) S_{a}^{-1}+K_{n}^{T} S_{\epsilon}^{-1} K_{n}\right]^{-1}\left[K_{n}^{T} S_{\epsilon}^{-1}\left(Y-F\left(X^{n}\right)\right)-S_{a}^{-1}\left(X^{n}-X_{a}\right)\right]
$$

where $X_{a}$ and $S_{a}$ denote the a priori known state vector and covariance matrix, respectively. The atmospheric composition data known a priori were taken from the climatological entire-year profile from the Whole Atmosphere Community Climate Model (WACCM) version 4 at AMY, between 1980 and 2020 [51]. Climatological AOD values, which were 0.3 for both mean $\left(X_{a}\right)$ and covariance value $\left(S_{a}\right)$, were obtained from AERONET data at AMY between 1999 and 2016.

The Jacobian matrix $\left(\mathrm{K}_{\mathrm{n}}\right)$ was calculated using the first-order partial derivative of $\mathrm{Y}$ and $X$ with physical perturbation. Here, $Y$ denotes the observed AERI radiance, while $F(X)$ is the simulated radiance by LBLDIS with the thermodynamic profile and aerosol information. The error covariance of observation $\left(S_{\epsilon}\right)$ was determined from the standard deviation of the calibrated imaginary radiance spectrum as a function of wavelength [26]. Additionally, $\gamma$ is the Levenberg parameter (LP), which functions as the damping factor with the weight differences between observation and the solution to the previous iteration step.

The optimized solution can be derived by minimizing the cost function (c), which is determined as follows:

$$
c=(Y-F(x))^{T} S_{\epsilon}^{-1}(Y-F(X))+\left(X_{a}-X\right)^{T} S_{a}^{-1}\left(X_{a}-X\right)
$$

A high LP value indicates that the prior information contributes significantly more than the observations. For low LP value, the observation is more crucial than the prior information. LP value varies at each iteration according to the following criteria:

$$
\begin{gathered}
\mathrm{R}=\left(\mathrm{c}_{\mathrm{n}}-\mathrm{c}_{\mathrm{n}+1}\right) /\left(\mathrm{c}_{\mathrm{n}}-\mathrm{c}_{\mathrm{n}+1, \mathrm{FC}}\right) \\
\left\{\begin{aligned}
\mathrm{R}<0.25, & \gamma_{\mathrm{n}+1}=10 \times \gamma_{\mathrm{n}} \\
0.25<\mathrm{R}<0.75, & \gamma_{\mathrm{n}+1}=\gamma_{\mathrm{n}} \\
0.75<\mathrm{R}, & \gamma_{\mathrm{n}+1}=0.5 \times \gamma_{\mathrm{n}}
\end{aligned}\right.
\end{gathered}
$$

where $\mathrm{R}$ represents the ratio of two cost functions (one is calculated at the next iteration using the optimal estimation approach, and the other is related to the linear evolution), as $c_{n+1, F C}$ is calculated by assuming $F\left(X^{n+1}\right)=F\left(X^{n}\right)+K_{n} d X^{n+1}$. When $R$ is less than 0.25 , the present iteration is considered to be diverging, and thus, LP increases by a factor of 10 in the next iteration step. LP is constantly maintained when $\mathrm{R}$ is within 0.25 and 0.75 . When $\mathrm{R}$ is greater than $0.75, \mathrm{LP}$ is reduced by a half. 
The convergence is determined at each iteration according to the following equation.

$$
\left(X^{n}-X^{n+1}\right)^{T} S^{-1}\left(X^{n}-X^{n+1}\right) \ll N
$$

where $\mathrm{N}$ is the dimensions of the state vector. Furthermore, $\mathrm{S}$ is a posterior error covariance matrix that allows for the sensitivity of the forward model, and the uncertainties in both the prior information and the observations to be propagated into the uncertainty of the solution. It is determined as follows:

$$
\mathrm{S}=\left(\gamma \mathrm{S}_{\mathrm{a}}^{-1}+\mathrm{K}_{\mathrm{n}}^{\mathrm{T}} \mathrm{S}_{\epsilon}^{-1} \mathrm{~K}_{\mathrm{n}}\right)^{-1}\left(\gamma^{2} \mathrm{~S}_{\mathrm{a}}^{-1}+\mathrm{K}_{\mathrm{n}}^{\mathrm{T}} \mathrm{S}_{\epsilon}^{-1} \mathrm{~K}_{\mathrm{n}}\right)\left(\gamma \mathrm{S}_{\mathrm{a}}^{-1}+\mathrm{K}_{\mathrm{n}}^{\mathrm{T}} \mathrm{S}_{\epsilon}^{-1} \mathrm{~K}_{\mathrm{n}}\right)^{-1}
$$

The convergence state is determined based on the difference in the state vectors between the current and the previous iteration step through the change in state vector; it is substantially smaller than the magnitude of error associated with the retrieval. Moreover, $\mathrm{RMS}_{\mathrm{n}+1}>$ $\gamma_{\mathrm{n}} \mathrm{RMS}_{\mathrm{n}}$ and a number of maximum iterations are used as the convergence criteria.

\section{Results}

\subsection{Sensitivity Test}

The magnitude of down-welling emitted radiance in the thermal infrared spectral region is significantly affected by the atmospheric state [52]. Therefore, we simulated the first sensitivity test using LBLDIS to investigate the impacts of various atmospheric thermodynamic profiles and aerosol in the spectral region of AERI. Three atmospheric profiles-U.S. Committee on Extension to the Standard Atmosphere 1976 (US76), Middle Latitude Summer (MLS), and Middle Latitude Winter (MLW) - were considered, with the same aerosol condition (1.0 of AOD for CA) and compared with the clear-sky condition (Figure 4).

The contribution of emitted radiance due to aerosol ranges widely from 700 to $1300 \mathrm{~cm}^{-1}$, including the atmospheric window, and is small, between 650 to $700 \mathrm{~cm}^{-1}$, where the strong absorption bands of $\mathrm{CO}_{2}$ exist. Although identical properties were applied, the magnitude and shape of the effect on the radiance (represented as residual in Figure $4 \mathrm{~b}$ ) differed as a function of the wavenumber as the different amounts of absorption by other gases, especially water vapor and temperature with Stefan-Boltzmann's law, affect the emission, and the radiance arrived at the ground in the thermal-IR regions. Moreover, the radiance can significantly change depending on the atmospheric humidity as the watervapor continuum is widely located in the IR regions. The radiance residuals are about 3-4 radiance units ( $\mathrm{RU} ; 1 \mathrm{~mW} /\left(\mathrm{m}^{2} \mathrm{sr} \mathrm{cm}^{-1}\right)$, which are approximately $20-30 \%$ of clear sky radiances. Thus, the TROPoe was employed to acquire the accurate thermodynamic profiles to reduce the uncertainty derived from the atmospheric states.

Figure 5 shows the effect of different aerosol types on radiation under the same atmospheric conditions (US76 atmospheric profile). The AODs are all set to 1.0. MC, representative of the marine region, which exhibits a different shape for the radiance residual spectrum than CA and UR despite having the same atmospheric conditions (Figure 5b). Compared with CA and UR, MC more significantly impacts the emitted radiance at relatively short wavenumbers $\left(700-900 \mathrm{~cm}^{-1}\right)$ than at a longer wavenumber (900-1200 $\left.\mathrm{cm}^{-1}\right)$. This is because the different aerosol type compositions afford different refractive indices. Furthermore, the emission coefficients of the sea salt are larger than those of the aerosol components (e.g., WASO, INSO, and SOOT) at short wavenumbers [9]; thus, MC emits more radiance at $700-900 \mathrm{~cm}^{-1}$. In contrast, the impact of CA and UR is significant at long wavenumbers $\left(900-1200 \mathrm{~cm}^{-1}\right)$ because the emission coefficient of INSO is larger than that of sea salt at long wavenumbers [9]. Additionally, the effects of the CA and UR on the radiance are not discernable because they have the same aerosol composition and only a slight difference in the number density. Therefore, we decided to use only $\mathrm{CA}$ and $\mathrm{MC}$ to represent the general state of the turbid atmosphere. 

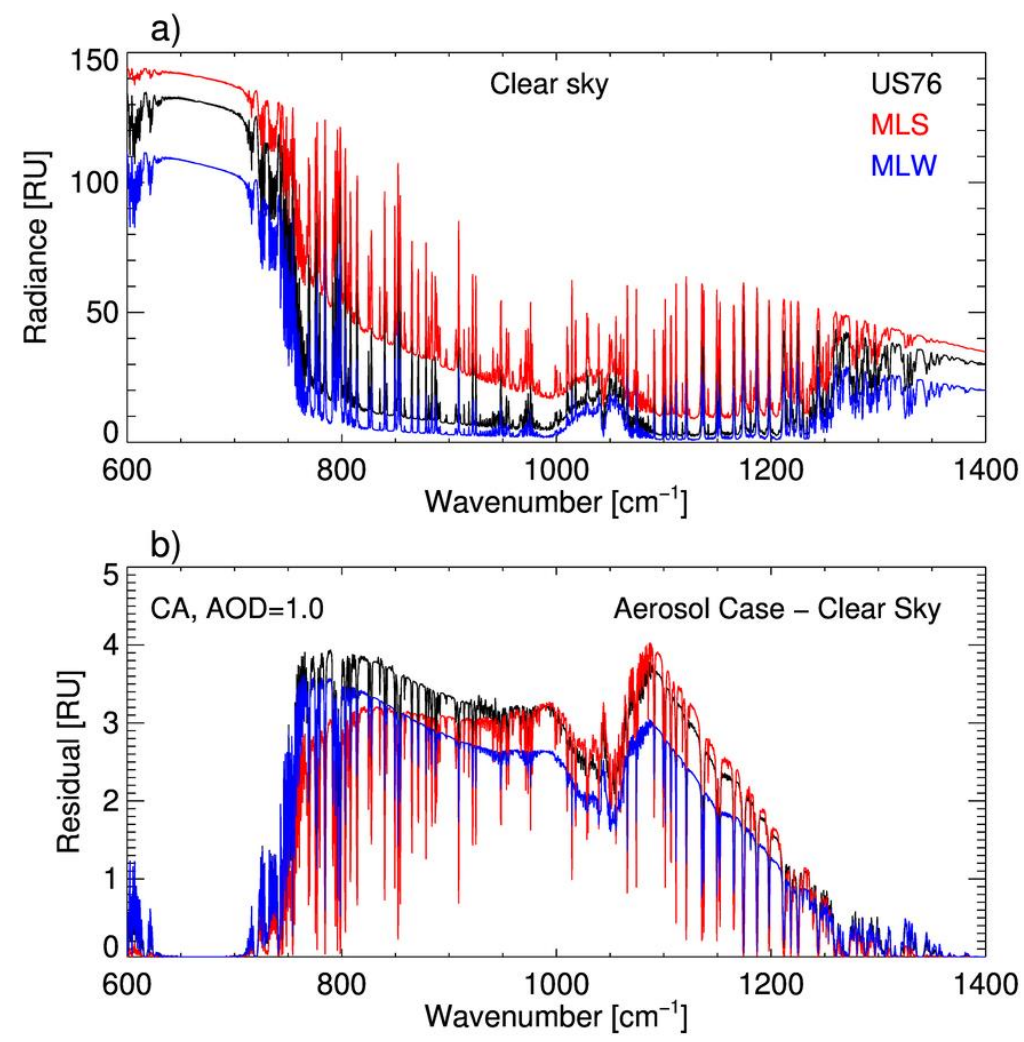

Figure 4. (a) The simulated clear sky radiance from LBLDIS for different atmosphere models, US76 (black), MLS (red), and MLW (blue). (b) The residual radiances between clear sky and turbid aerosol conditions. The aerosol was set as 1.0 of AOD for CA. The "radiance unit (RU)" is $1 \mathrm{~mW} /\left(\mathrm{m}^{2} \mathrm{sr} \mathrm{cm}^{-1}\right)$.
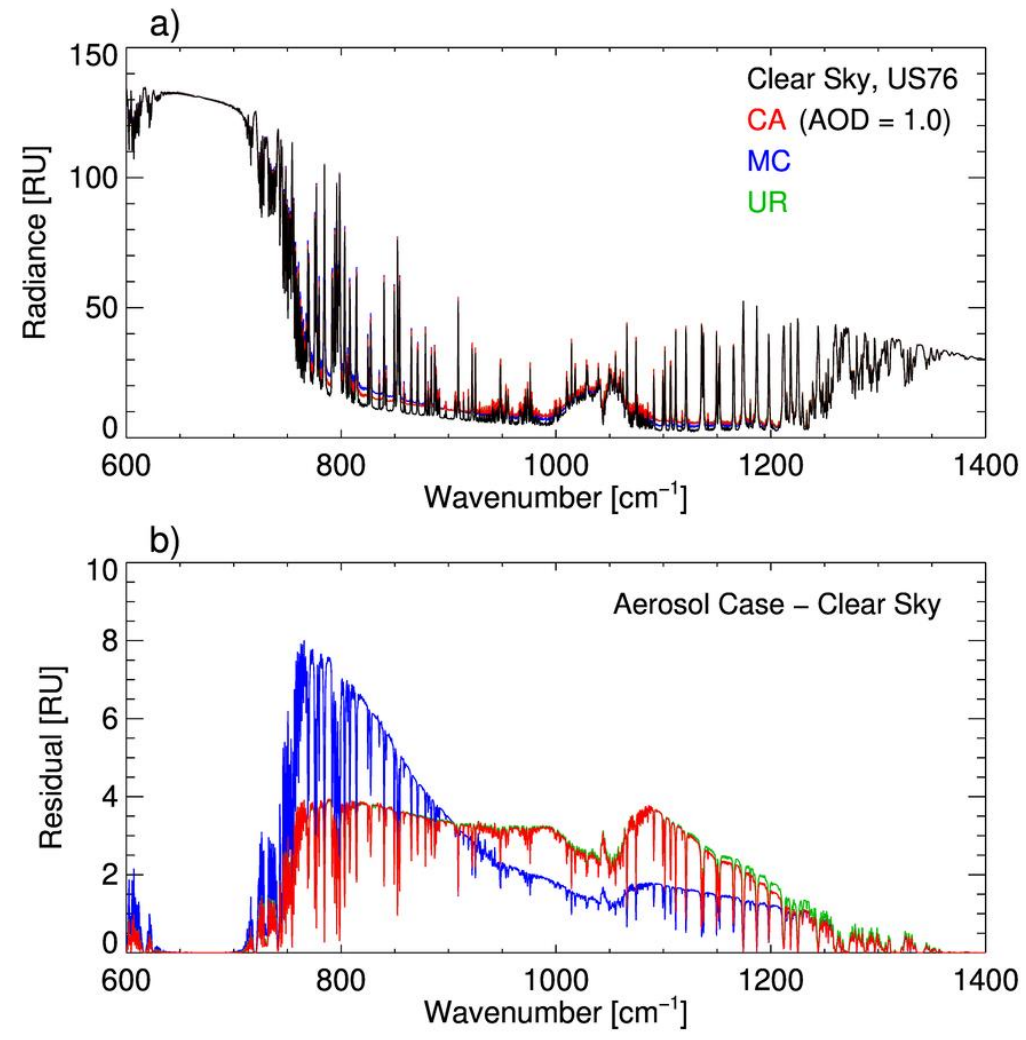

Figure 5. (a) The simulated radiance from LBLDIS for clear sky (black) and different mixture aerosol types: CA (red), UR (green), and MC (blue). (b) The residual of radiances between clear sky and aerosol cases set as 1.0 of AOD. 
Figure 6 shows the impacts of various AODs under the same atmospheric conditions and aerosol type. A US76 atmospheric profile was used, and various AODs, ranging from 0.3 to 1.0 of $\mathrm{CA}$, were simulated. The downwelling emitted radiance increased with a high AOD. The maximum impacts (approximately $4 \mathrm{RU}$ ) occurred at around $800 \mathrm{~cm}^{-1}$ when AOD was 1.0, which is equivalent to about $30 \%$ of the radiance of an aerosol-free atmosphere. When compared with the noise level of AERI, which is assumed to be $1 \%$ of radiance, the radiance emitted from aerosol is not negligible even when AOD is 0.1, except for the $\mathrm{CO}_{2}$ absorption bands. From those simulation studies, the fitting windows to estimate AOD were determined in the ARAOE algorithm (Table 2).
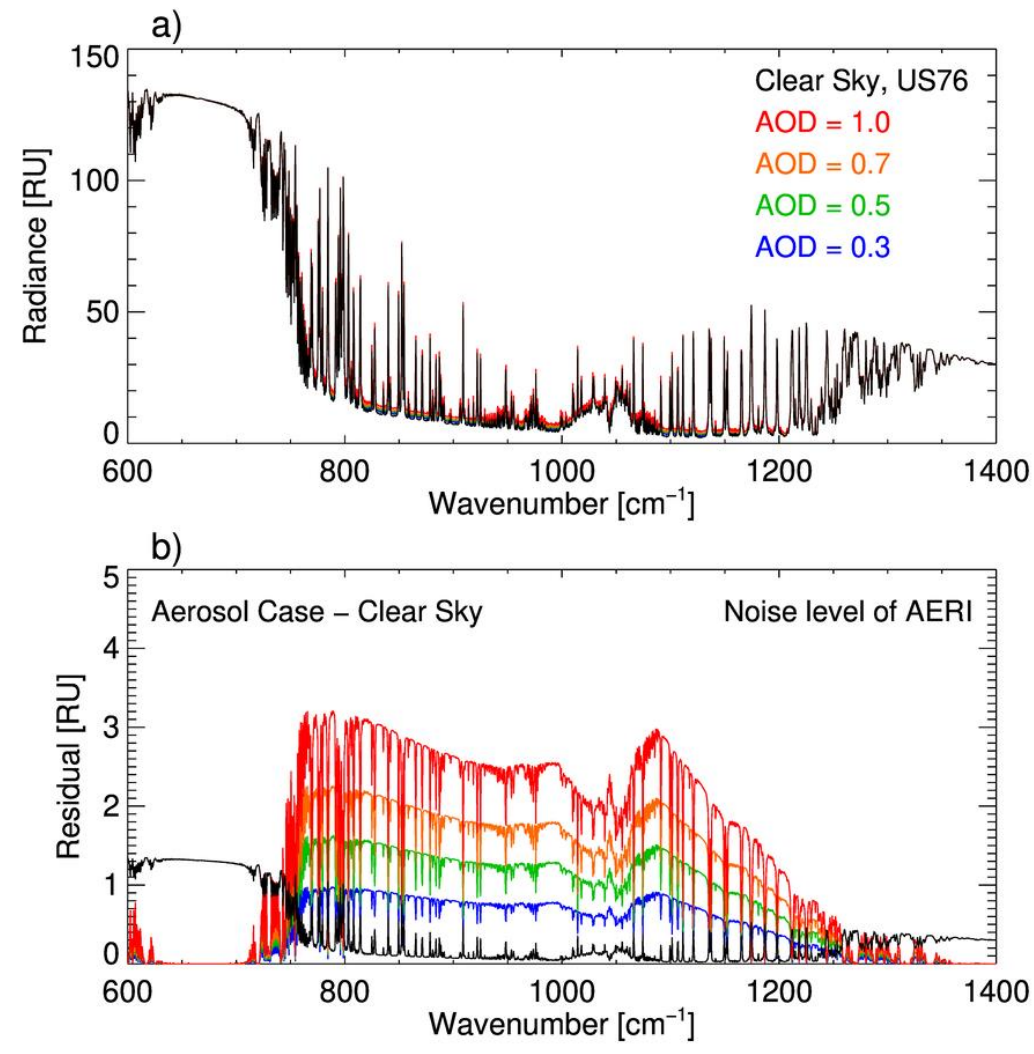

Figure 6. (a) The simulated radiance from LBLDIS for clear sky (black) and various AOD conditions ranging from 0.3 to 1.0. (b) The residual of radiances between clear sky and each AOD state. The aerosol type was CA, and the US76 standard atmosphere model was used for the thermodynamic profile.

Lastly, we tested the change in the degree of freedom for the signal (DFS) for AOD in the retrieval algorithm depending on humidity, which affects the IR regions, including the fitting windows used in this study. The DFS, which represents the number of independent pieces of information from the observation used in the solution, can be computed as the traces of the averaging kernel matrix $(\mathrm{A})$ :

$$
\mathrm{A}=\left(\gamma \mathrm{S}_{\mathrm{a}}^{-1}+\mathrm{K}_{\mathrm{n}}^{\mathrm{T}} \mathrm{S}_{\epsilon}^{-1} \mathrm{~K}_{\mathrm{n}}\right)^{-1} \mathrm{~K}_{\mathrm{n}}^{\mathrm{T}} \mathrm{S}_{\epsilon}^{-1} \mathrm{~K}_{\mathrm{n}}
$$

The atmosphere profiles for simulation were randomly selected to consider the various humidity conditions from ERA-5 data in 2010 at AMY. The precipitable water vapor (PWV) was used to represent the atmospheric humidity as follows:

$$
\mathrm{PWV}=\int_{0}^{\infty} \frac{\mathrm{r}_{\mathrm{z}}}{\mathrm{g}} \mathrm{dp}
$$


where $r_{z}$ is the water-vapor mixing ratio, $g$ is the gravitational acceleration, and $p$ is the pressure level. The AODs were set to 0.1 (low), 0.5 (medium), and 1.0 (high) to represent the different atmospheric turbidities for the CA and MC types.

Table 2. Spectral region used in the retrieval of temperature, water-vapor mixing ratio, and AOD.

\begin{tabular}{|c|c|c|}
\hline State Vector & Starting Wavenumber $\left(\mathrm{cm}^{-1}\right)$ & Ending Wavenumber $\left(\mathrm{cm}^{-1}\right)$ \\
\hline \multirow{3}{*}{ Temperature } & 612.0 & 618.0 \\
\hline & 624.0 & 660.0 \\
\hline & 674.0 & 713.0 \\
\hline Water-vapor mixing ratio & 538.0 & 588.0 \\
\hline \multirow{12}{*}{ AOD } & 770.9 & 774.8 \\
\hline & 785.9 & 790.7 \\
\hline & 809.0 & 812.9 \\
\hline & 815.3 & 824.4 \\
\hline & 828.3 & 834.6 \\
\hline & 842.8 & 848.1 \\
\hline & 860.1 & 864.0 \\
\hline & 872.2 & 877.5 \\
\hline & 891.9 & 895.8 \\
\hline & 898.2 & 905.4 \\
\hline & 926.6 & 939.7 \\
\hline & 959.9 & 964.3 \\
\hline
\end{tabular}

Figure $7 \mathrm{a}-\mathrm{c}$ show the bias errors, which are the differences between retrieved AOD and assumed AOD. The bias errors were very small when PWV is smaller than $2.5 \mathrm{~cm}$ and increased with a high PWV. MC had a smaller error and was less sensitive to the amount of the PWV than CA because the signal emitted from the MC aerosol type is stronger than the CA aerosol type in Figure 5. The bias error of MC is less than 5\%, even though the PWV is more than $6 \mathrm{~cm}$. When AOD is 0.1 (low), the bias error and retrieval uncertainty are larger than the AODs, at 0.5 (medium) and 1.0 (high). This is because the signal from aerosol is weak when AOD is a low. Additionally, the retrieved AOD typically has a positive bias when AOD is 0.1 and a negative bias when AOD is 0.5 and 1.0. This is because of the a prior value we used for AOD as 0.3.

The DFS sensitivity as a function of the PWV (Figure 7d-f) show similar characteristics to bias error. Over $2.5 \mathrm{~cm}$ of PWV, the DFSs of CA and MC start to decrease. The DFS for AOD at 0.1 is generally lower and has an inconsistent habit, depending on PWV, compared with the DFS for AOD at 0.5 and 1.0. This is also because the signal of the radiance emitted from the aerosol is weak at a low AOD. Additionally, the DFS for CA is more sensitive to the PWV than that of MC and decreases over $5 \mathrm{~cm}$ of PWV. When the PWV is $6 \mathrm{~cm}$, the DFS for CA decreased by 20-30\%, whereas MC only slightly decreased. As the radiance emitted from the MC type is greater than that of CA, as shown in Figure 5, MC inherently requires more signals to obtain the information needed for retrieval. Nevertheless, CA has still information, even in a highly humid atmosphere (DFS > 0.8).

\subsection{Verification of AOD Retreival Algorithm: Case Study}

The retrieval performance of ARAOE was evaluated using the AERI-observed radiance at the AMY observation site. As mentioned in Section 2, the available temporal data for AERI at AMY were limited and sparse; thus, we selected a specific period that had continuous data for the entire day: 21 October 2010.

Figure 8 shows the retrieved time series of temperature and the water-vapor mixing ratio profiles obtained using the TROPoe. The figure reproduces the diurnal variation in the temperature, wherein the temperature around the surface increases in the afternoon due to the solar heating and decreases at nighttime due to the radiation cooling. The mean PWV was $1.64 \mathrm{~cm}$ in this case study, so the uncertainty derived from a high PWV value was negligible. 

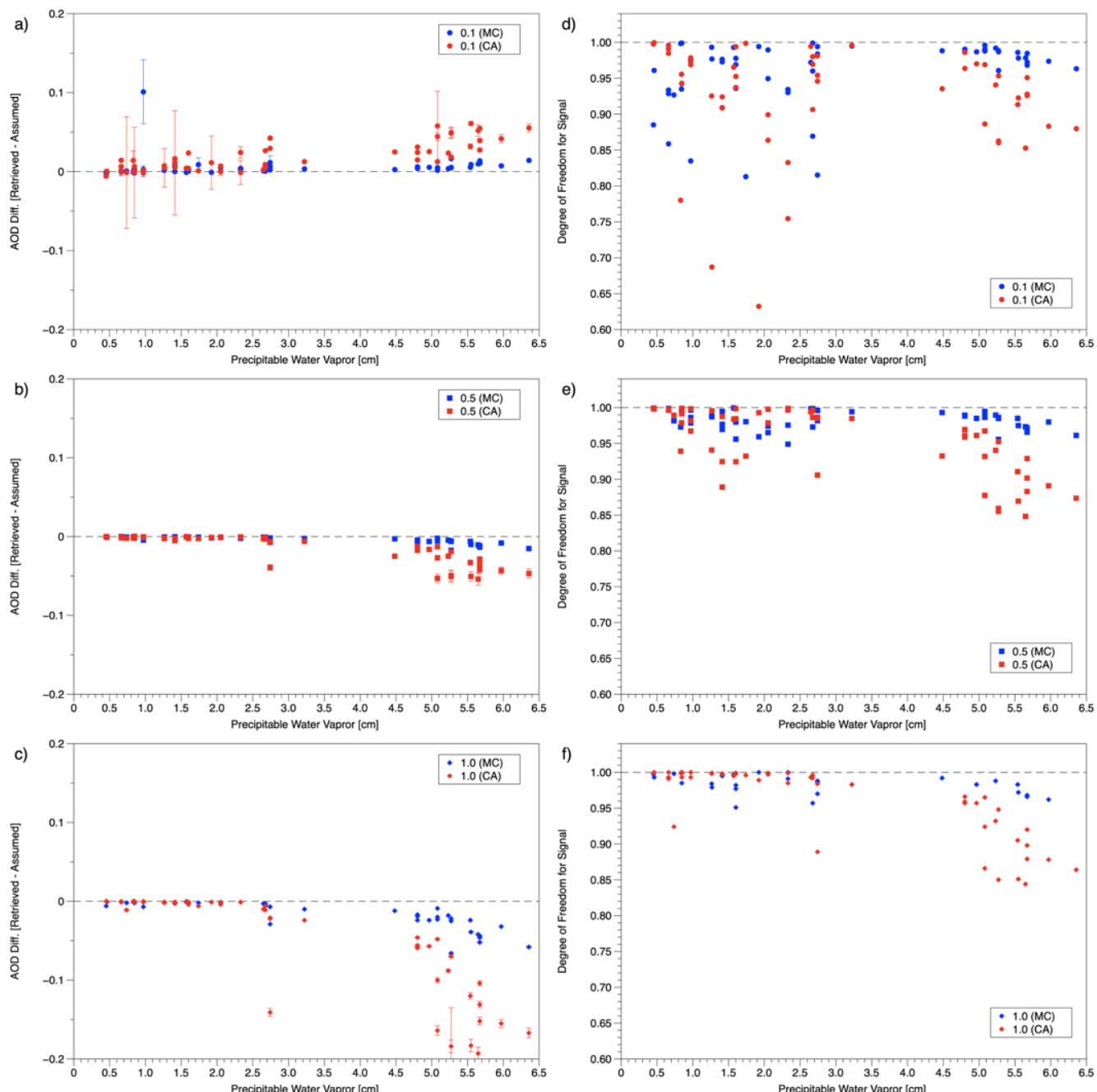

Figure 7. $(\mathbf{a}-\mathbf{c})$ The difference between the retrieved and assumed AOD and $(\mathbf{d}-\mathbf{f})$ DFS as a function of the PWV. These estimated results were acquired from the simulated radiance using the thermodynamic profiles from ERA-5 data, and AOD was assumed to be 0.1 (circle), 0.5 (square), and 1.0 (diamond) for the CA and MC types.

To verify the thermodynamic profiles retrieved from the AERI observations, the modified Taylor diagram [53] was employed; this is a statistical technique used to demonstrate the retrieval efficiency and similarity between two datasets. ERA- 5 data were used for comparison. The Pearson correlation coefficient (R) and standard deviation ratio (SDR) between the retrieved variables and ERA-5 data are defined as

$$
\begin{gathered}
\mathrm{R}=\frac{\frac{1}{\mathrm{~N}} \sum_{\mathrm{z}=0}^{4 \mathrm{~km}}[\mathrm{~m}(\mathrm{z})-\overline{\mathrm{m}}][\mathrm{a}(\mathrm{z})-\overline{\mathrm{a}}]}{\sigma_{\mathrm{m}} \sigma_{\mathrm{a}}} \\
\mathrm{SDR}=\sigma_{\mathrm{a}} / \sigma_{\mathrm{m}}
\end{gathered}
$$

where $\mathrm{N}$ denotes the number of profiles, $\mathrm{m}(\mathrm{z})$ represents the ERA- 5 profile, and $\mathrm{a}(\mathrm{z})$ is the retrieved thermo-dynamic profile. The mean values $(\overline{\mathrm{m}}$ and $\overline{\mathrm{a}})$ and standard deviation $\left(\sigma_{\mathrm{m}}\right.$ and $\sigma_{\mathrm{a}}$ ) were calculated over the altitude between 0 and $4 \mathrm{~km}$. For example, $\mathrm{R}=1$ and $\mathrm{SDR}=1$ is in an ideal place between the two datasets.

Figure 9 shows the results of the modified Taylor diagram generated from each thermodynamic profile in Figure 6. The points on the diagram cluster are mainly distributed around $\mathrm{R}=0.95$ and $\mathrm{SDR}=1.1$ for temperature and around $\mathrm{R}=0.92$ and $\mathrm{SDR}=0.9$ for the water-vapor mixing ratio. These results are similar to those of a previous study [31] and 
demonstrate that the retrieved thermodynamic profiles agree well with the ERA-5 profiles $(\mathrm{R}>0.92$ and $0.9<\mathrm{STD}<1.1)$.
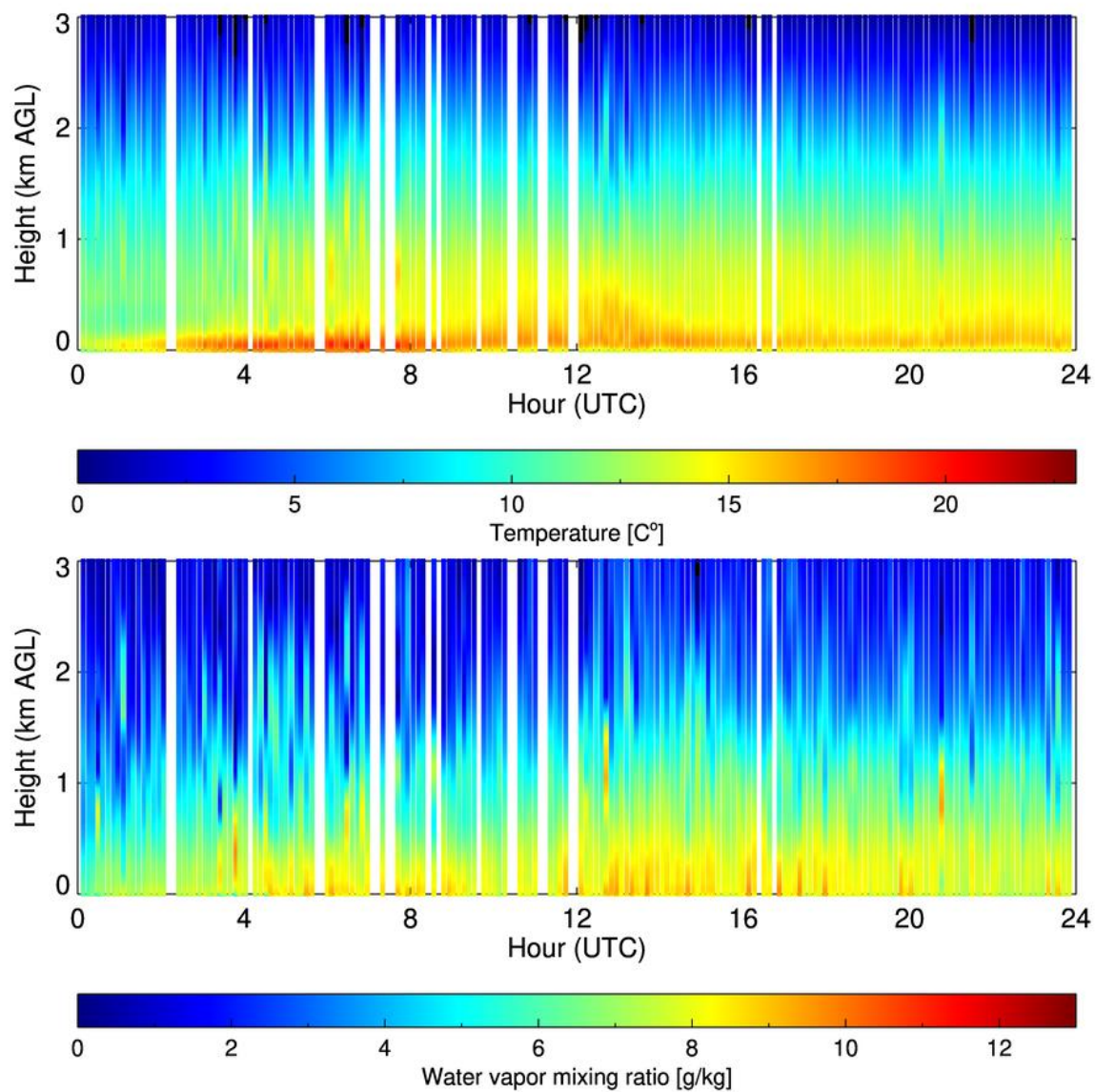

Figure 8. Time series of the retrieved temperature (top) and water-vapor mixing ratio (bottom) using the TROPoe on 21 October 2010 at AMY (local time $=\mathrm{UTC}+9 \mathrm{~h}$ ).

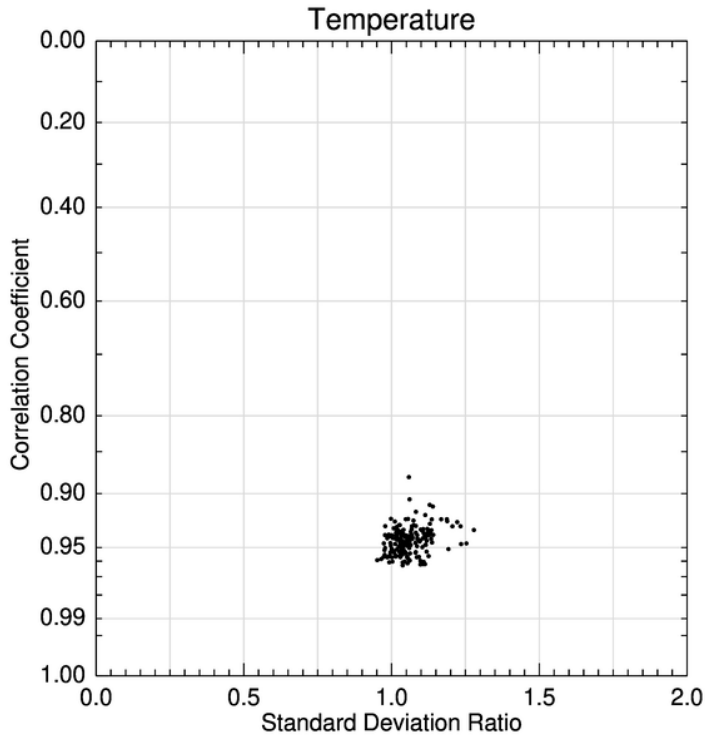

(a)

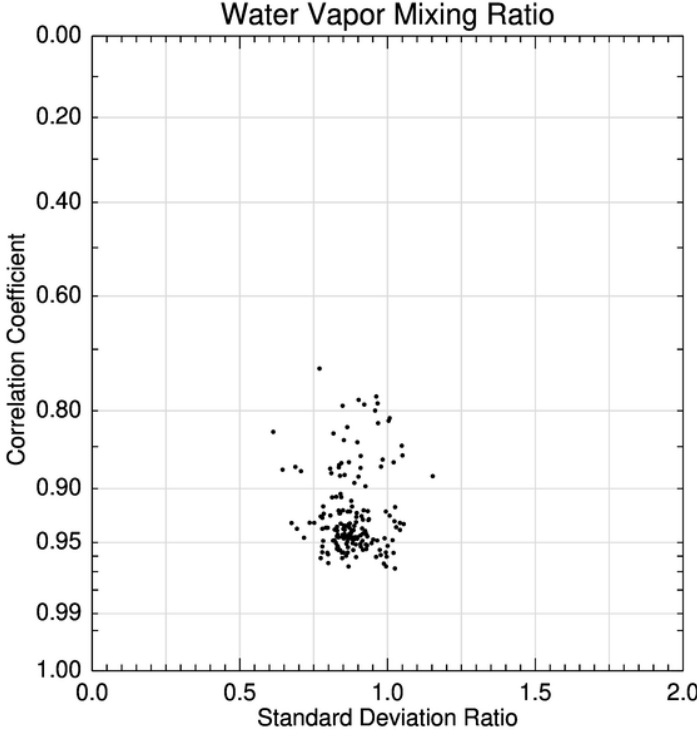

(b)

Figure 9. Modified Taylor diagrams showing the correlation coefficient and SDR between the ERA-5 data and retrieved profiles of (a) temperature and (b) water-vapor mixing ratio on 21 October 2010 at the AMY. 
Finally, the AOD retrieved from the AERI observations with assumption of two aerosol types (CA and MC) was compared with the GAW-PFR observations as a function of time (Figure 10). The GAW-PFR data exist only for the daytime, from 00 to 08 UTC (09 to 16 local time), as they observes the shortwave radiance incoming from the sun. Here, the observed AOD from GAW-PFR ranged from 0.4 at 00 UTC to 1.2 at 07 UTC. This demonstrates that the high temporal resolution beneficially captures the evolution of pollutions in the atmosphere. As mentioned in a previous sensitivity test, due to the emissivity difference between MC and CA in the spectral bands used in the ARAOE algorithm, the AOD derived for MC was, overall, slightly lower than those derived for CA.

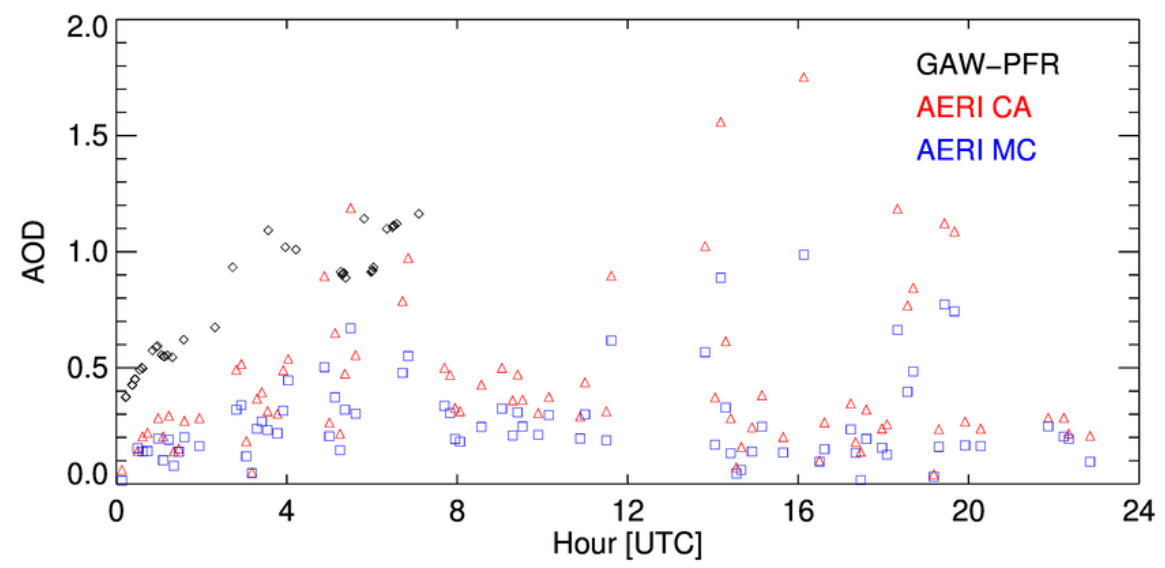

Figure 10. The time series of the retrieved AOD assuming different aerosol types, CA (red triangle) and MC (blue square), and that observed (black, diamond) using GAW-PFR.

Additionally, the pollution events were higher than the climatological value of mean (0.3) and standard deviation (0.3) obtained from AERONET at AMY. The AODs retrieved from the AERI observations are likely to have been quantitatively underestimated compared to the AOD observed during the daytime. However, their diurnal evolutions, such as the growth trend over time, are similar. MC-type AODs were lower than CA-type AODs because the emissivity of the $\mathrm{MC}$ in the spectral bands used in the algorithm is greater than that of the CA. In addition, this retrieval characteristic was clearly revealed in the sensitivity test according to the aerosol type, and while CA and UR had similar results regardless of the variation in AOD, the retrieval error of AOD for the MC-type increased as AOD increased (Figure S2 and Table S1). The slight AOD difference between 03 and 04 UTC may be because of the contamination of some signals by transparent cirrus or fragment clouds, or thin mist/haze. In addition, the cause of this discrepancy could be inherently affected by the sensitivity of AERI. GAW-PFR is sensitive to both fine and coarse particles, and AERI radiance is primarily affected by the larger particles in the size distribution. Therefore, when very fine aerosol particles are present in the atmosphere, AERI's radiance responds less sensitively to fine mode AOD; then, the AOD derived by ARAOE can be underestimated compared with that from the GAW-PFR. Moreover, several steep increases in the AOD events were observed during the nighttime, while the AODs were maintained in the $0.2-0.5$ range.

Figure 11 shows an example of the downwelling radiance spectrum of AERI observations and the radiance spectrum simulated by LBLDIS for a clear sky and aerosol case at 04:53 UTC on 21 October 2010. The simulated radiance for clear sky (driven using thermodynamic profiles from the TROPoe) was lower than the radiance observed in the spectral regions for aerosol retrieval. These differences in the radiance spectrum are related to the impacts of aerosol types. Furthermore, the simulated radiance from ARAOE matched the observation at $800-1200 \mathrm{~cm}^{-1}$ and the retrieved AOD of 0.9 matched the AOD of 0.91 from the GAW-PFR. 


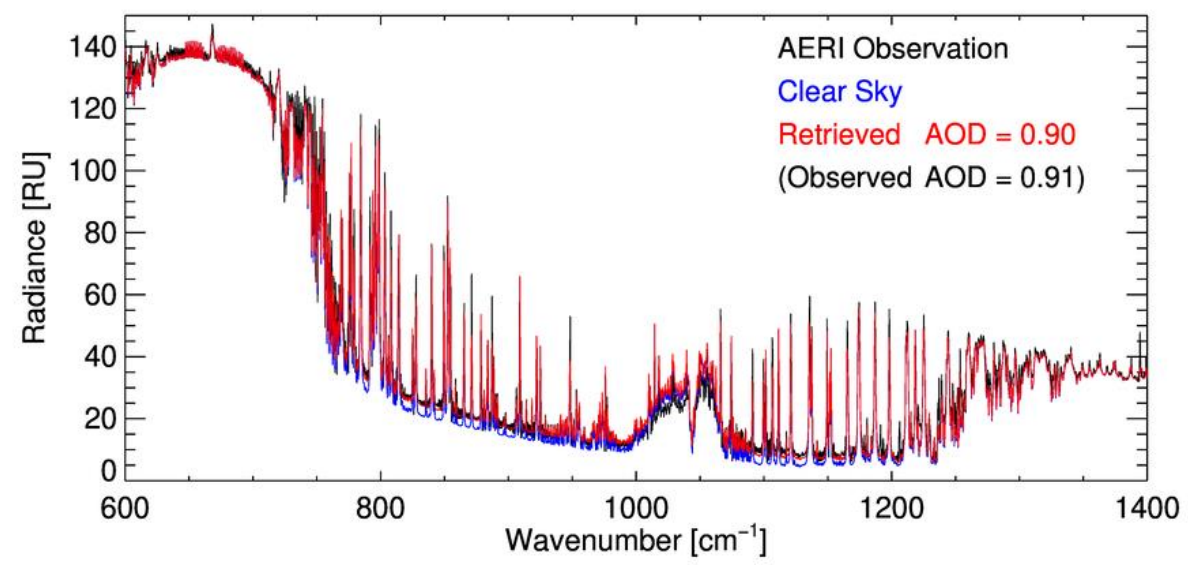

Figure 11. AERI-observed radiance (black), simulated radiance with aerosol model CA (red), and simulated radiance without aerosol information (blue).

Figure 12 shows the variations in AOD and root mean square error (RMSE) between the observed and simulated radiance at each iteration step until the algorithm reached the optimized solution at 04:53 UTC on 21 October 2010. At each iteration step, the AOD convergence process was clearly revealed. The AOD increased from 0.3 in the first iteration to 0.9 , which is a convergent state that in good agreement with the AOD of 0.91 from GAWPFR. Simultaneously, the RMSE of radiance decreased from 3.4 to $2.2 \mathrm{RU}$ with each iteration step. These results show the good performance of the retrieval algorithm and suggest the possibility of AOD retrieval using infrared radiance with a well-defined thermodynamic profile and an aerosol model.

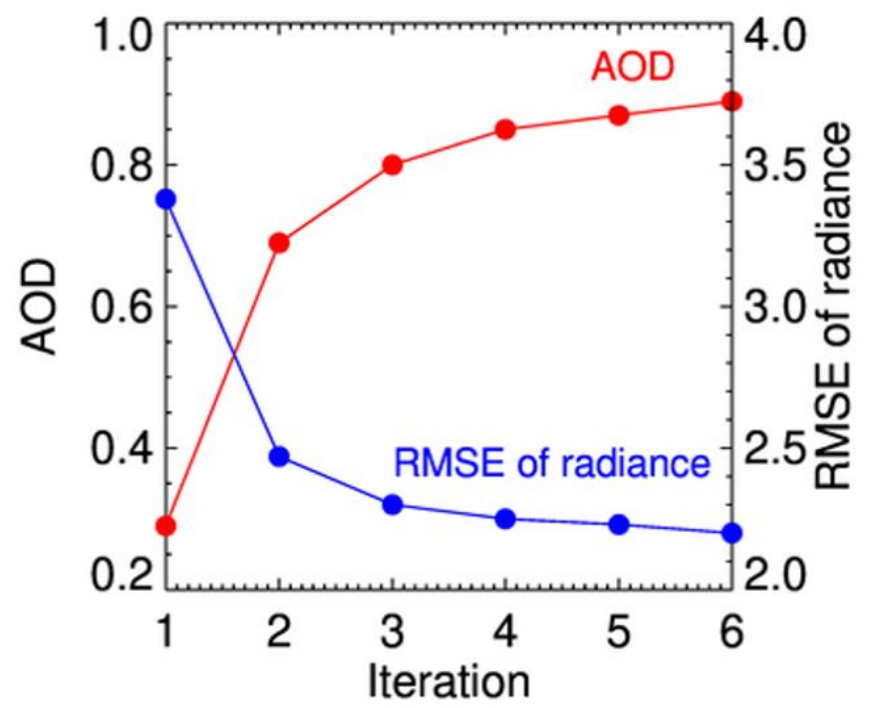

Figure 12. Variations in the AOD and RMSE of radiance between observation and simulated radiance at each iteration step in the retrieval process at 0453 UTC on 21 October 2010.

\section{Discussion}

ARAOE employs broad infrared spectral bands that are sensitive to aerosols used to derive the AOD from the hyperspectral downwelling radiance that was emitted, measured from AERI, based on OEM. Therefore, ARAOE is sensitive to the magnitude of the radiance spectrum simulated by the RTM, considering the atmospheric vertical structures (temperature and water-vapor mixing ratio), chemical profiles, and aerosol effects as well as the observation quality in AERI due to the characteristics of the infrared spectral region.

Herein, a comparison with the ERA-5 and GAW-PFR data shows that the ARAOE coupled with the TROPoe accurately estimated the atmospheric profiles and AOD, respectively. 
However, the AOD obtained using ARAOE was somewhat underestimated compared with that obtained using GAW-PFR in states of relatively high AOD (over 0.5). This could be due to the uncertainty derived from the small aerosol particles, showing that AERI is insensitive, but GAW-PFR is able to detect this.

In ARAOE, the aerosol effect was simulated for several types of aerosol mixture and fixed vertical distributions from the OPAC database. However, the optical and physical properties of aerosols are different under the actual atmospheric conditions. For example, the physical and optical properties of Asian dust are very different compared with the general aerosol types, especially as Asian dust is largely composed of large-size particles; thus, it will be beneficial to retrieve AOD during the Asian dust event with the ARAOE algorithm. Moreover, many lidar-based aerosol studies [54-56] show that the vertical distribution shapes assumed in OPAC can be different. Turner [56] showed that the aerosol scale height at the Southern Great Plains is much lower $(2 \mathrm{~km})$ than the OPAC scale height used in this study $(8 \mathrm{~km})$.

Additionally, it will be useful to look at whether the type of aerosol from the OPAC database can be distinguished in the previous stage using certain wavelength bands (especially adding a $1100-1150 \mathrm{~cm}^{-1}$ region where the refractive indices vary dramatically according to the aerosol type, as shown in Figure S1), in which the residual from the radiance spectrum is significantly different from the clear sky state, as shown in Figure 4. Moreover, the aerosol type was further subdivided, and if the vertical information (e.g., extinction coefficient and depolarization ratio) using the multi-wavelength Raman lidar [56,57], which simultaneously measures this along with AERI, is simultaneously employed, then the AOD retrieval error can be reduced.

The presence of the fractional clouds or cirrus in the clean atmosphere can overestimate the AOD in regions with clear skies or less turbid aerosol conditions because the emitted radiance in these regions may be mistakenly recognized as the effect of aerosol. Therefore, the cloud process should include additional correction or filtering to minimize the cloud effect. If the sky cover identified from the hemispheric sky images measured by the total sky imager (TSI), or the cloud fraction or cloud type information derived from a high-resolution satellite are utilized, the contaminated signals caused by cirrus or fractional clouds could be distinguished using an appropriate threshold value (e.g., cloud cover < 0.3). Furthermore, if an algorithm that calculates cloud information from AERI, such as the mixed-phase cloud property retrieval algorithm (MIXCRA [58]), is used for cases classified as optically thin clouds, it can be utilized to acquire a cloud's microphysical information.

In the present study, the daytime AOD, retrieved by ARAOE from AERI, was evaluated with that of GAW-PFR, and in the future, the nighttime AOD can be directly/indirectly evaluated with the aerosol information derived from the ground-based aerosol lidar or the Cloud-Aerosol Lidar with Orthogonal Polarization (CALIOP), which are onboard the Cloud-Aerosol Lidar and Infrared Pathfinder Satellite Observation (CALIPSO).

Furthermore, in future studies, we will variably consider the chemical composition of the atmosphere, such as $\mathrm{CO}_{2}$, for which the transmittance is widely distributed in the AERI spectral region, using the chemical transport model or satellite observation instead of the fixed concentration from the current atmospheric models (US76, MLS, and MLW).

\section{Summary and Conclusions}

In this study, we investigated the possibility of AOD retrieval based on OEM using the AERI observations at the AMY observation site. Through the sensitivity tests, we showed that the effects of the downwelling radiance that was emitted depend on the different atmospheric thermodynamic profiles as well as on the physical and optical properties of aerosol. Therefore, ARAOE was coupled with the TROPoe to obtain an accurate vertical temperature structure and water-vapor information and with LBLDIS to simulate the radiance using a generalized aerosol model. The optical and physical properties of aerosol were adopted from the OPAC database, and a mixed CA and MC aerosol type was considered. 
The atmospheric profiles retrieved from the TROPoe and the AOD retrieved from ARAOE were compared with the ERA-5 reanalysis data and GAW-PFR observations, respectively. The thermodynamic profiles agreed with those from the ERA-5 data through the modified Taylor diagram. The retrieved AODs displayed the same growth trend, although this tends to be slightly underestimated compared with that of GAW-PFR. A possible reason for this underestimation is that the AOD retrieved with ground-based remote sensing in the IR region comprised numerous uncertainties from thermodynamic profiles, radiative transfer model, absorption model, trace gases, and the aerosol's assumed optical and physical characteristics as well as the inherent AERI instrument [59]. However, the results showed that the retrievals accurately captured the observation trend and that the radiance simulated with the aerosol model exhibited better performance when obtained with the AERI-observed radiance compared with the radiance simulated without aerosol information. Thus, these results show the possibility of retrieving AOD using infrared radiance using accurate thermodynamic profiles and an aerosol model.

Herein, limited AERI samples were used to investigate the possibility of AOD retrieval in the infrared region due to the limitations of continuous AERI operation at AMY. However, AERI is operated worldwide in various climate and aerosol conditions by the ARM. Therefore, possible future work includes examining the AOD retrieved using AERI-observed radiance at worldwide observation sites with long-period data. Numerous observations should allow for an in-depth comparison between the retrieved and observed AOD and for the study of aerosol characteristics under different aerosol conditions.

Supplementary Materials: The following supporting information can be downloaded at: https: / / www.mdpi.com/article/10.3390/rs14020407/s1, Figure S1: Refractive indices (parts of real and imaginary) of each aerosol type, insoluble (INSO), soot (SOOT), water soluble (WASO), sea salt accumulated mode (SSAM), sea salt coarse mode (SSCM), respectively. The values for WASO represent $50 \%$ of relative humidity. The gray shaded regions are the fitting window for AOD retrieval in ARAOE (Table 2 in main text); Figure S2: Sensitivity test of ARAOE using synthetic data according to the aerosol types of $\mathrm{CA}, \mathrm{UR}$, and $\mathrm{MC}$, respectively. The synthetic radiance spectrum within AERI spectral range consisted of US76 atmospheric data with various AODs of $0.1,0.5,1.0$, and 1.5 for (a) CA and (b) MC aerosol types.; Table S1: Results of retrieved AOD for different aerosol type assumption.

Author Contributions: Conceptualization, H.C.; methodology, H.C. and J.S.; software, J.S. and H.C.; validation, J.S.; formal analysis, H.C. and J.S.; investigation, J.S., H.C. and Y.O.; writing-original draft preparation, J.S. and H.C.; writing-review and editing, H.C., J.S. and Y.O.; visualization, J.S. and H.C.; supervision, H.C.; project administration, H.C.; funding acquisition, H.C. and Y.O. All authors have read and agreed to the published version of the manuscript.

Funding: This research was supported by the Basic Science Research Program through the National Research Foundation of Korea (NRF) funded by the Korean government (MOE) (no. NRF2021R1I1A1A01045062) and the Korea Meteorological Administration Research and Development Program "Development of Monitoring and Analysis Techniques for Atmospheric Composition in Korea" under grant (KMA2018-00522).

Institutional Review Board Statement: Not applicable.

Informed Consent Statement: Not applicable.

Data Availability Statement: The data that support the findings of this study are available from the corresponding author upon reasonable request.

Acknowledgments: We express special thanks to Young-Suk Oh of the National Institute of Meteorological Sciences (NIMS), Korea Meteorological Administration (KMA) for providing the AERI data. The authors express their gratitude to the reviewers for their valuable comments and suggestions for improving this manuscript.

Conflicts of Interest: The authors declare no conflict of interest. 


\section{Abbreviations}

\begin{tabular}{|c|c|}
\hline AERI & Atmospheric Emitted Radiance Interferometer \\
\hline AOD & Aerosol Optical Depth \\
\hline ARAOE & $\begin{array}{l}\text { Aerosol Optical Depth Retrieval Algorithm from AERI using the } \\
\text { Optical Estimation Method }\end{array}$ \\
\hline ARM & Atmospheric Radiation Measurement \\
\hline AMY & AnMYeon \\
\hline CA & Continental Average \\
\hline CALIOP & Cloud-Aerosol Lidar with Orthogonal Polarization \\
\hline CALIPSO & Cloud-Aerosol Lidar and Infrared Pathfinder Satellite Observation \\
\hline DISORT & Discrete Ordinates Radiative Transfer \\
\hline DFS & Degrees of Freedom for the Signal \\
\hline ECMWF & European Centre for Medium-Range Weather Forecasts \\
\hline ERA-5 & ECMWF Reanalysis version 5 \\
\hline ESRL & Earth System Research Laboratory \\
\hline FWHM & Full Width at Half Maximum \\
\hline FTIR & Fourier Transfer Infrared \\
\hline GAW-PFR & Global Atmosphere Watch Precision-Filter Radiometer \\
\hline HITRAN & HIgh-Resolution Transmission molecular absorption database \\
\hline INSO & Water-Insoluble \\
\hline KGAWO & Korea Global Atmosphere Watch Observatory \\
\hline KMA & Korean Meteorological Administration \\
\hline LBLRTM & Line-By-Line Radiative Transfer Model \\
\hline LP & Levenberg Parameter \\
\hline $\mathrm{MC}$ & Maritime Clean \\
\hline MLS & Middle Latitude Summer \\
\hline MLW & Middle Latitude Winter \\
\hline MODIS & Moderate-Resolution Imaging Spectroradiometer \\
\hline MT_CKD & MlawerTobinCloughKneizysDavies \\
\hline MWR & Microwave Radiometer \\
\hline NOAA & National Oceanic and Atmospheric Administration \\
\hline OEM & Optimal Estimation Method \\
\hline OMAERUV & OMI Near-Ultraviolet Aerosol Retrieval Algorithm \\
\hline OMI & Ozone Monitoring Instrument \\
\hline OPAC & Optical Properties of Aerosols and Clouds \\
\hline PWV & Precipitable Water Vapor \\
\hline RMSE & Root Mean Square Error \\
\hline RU & Radiance Units \\
\hline SKYNET & Sky Radiometer Network \\
\hline SSEC & Space Science and Engineering Center \\
\hline SURFRAD & Surface Radiation Budget Observing Network \\
\hline TROPoe & Tropospheric Optimal Estimation Retrieval Algorithm \\
\hline UR & Urban \\
\hline US76 & U.S. Committee on Extension to the Standard Atmosphere 1976 \\
\hline WACCM & Whole Atmosphere Community Climate Model \\
\hline WASO & Water-Soluble \\
\hline WFR-Chem & Weather Research and Forecasting Model Coupled with Chemistry \\
\hline $\mathrm{WMO}$ & World Meteorological Organization \\
\hline WORCC & World Optical Depth Research and Calibration Center \\
\hline
\end{tabular}

\section{References}

1. Charlson, R.J.; Schwartz, S.E.; Hales, J.M.; Cess, R.D.; Coakely, J.J.; Hansen, J.E.; Hofmann, D.J. Climate forcing by anthropogenic aerosols. Science 1992, 255, 423-430. [CrossRef] [PubMed]

2. $\quad$ Panicker, A.S.; Lee, D.I.; Kumkar, Y.V.; Kim, D.; Maki, M.; Uyeda, H. Decadal climatological trends of aerosol optical parameters over three different environments in South Korea. Int. J. Clim. 2013, 33, 1909-1916. [CrossRef] 
3. Stocker, T.F.; Qin, D.; Plattner, G.K.; Tignor, M.M.B.; Allen, S.K.; Boschung, J.; Nauels, A.; Xia, Y.; Bex, V.; Midgley, P.M. Climate Change 2013 the Physical Science Basis: Working Group I Contribution to the Fifth Assessment Report of the Intergovernmental Panel on Climate Change; Cambridge University Press: Cambridge, UK; New York, NY, USA, 2013; ISBN 9781107415324.

4. Choi, H.; Lee, K.-M.; Seo, J.; Bae, J. The Influence of Atmospheric Composition on Polarization in the GEMS Spectral Region. Asia-Pac. J. Atmos. Sci. 2021, 57, 587-603. [CrossRef]

5. Jung, Y.; Kim, J.; Kim, W.; Boesch, H.; Lee, H.; Cho, C.; Goo, T.Y. Impact of aerosol property on the accuracy of a $\mathrm{CO}_{2}$ retrieval algorithm from satellite remote sensing. Remote Sens. 2016, 8, 322. [CrossRef]

6. Patadia, F.; Levy, R.C.; Mattoo, S. Correcting for trace gas absorption when retrieving aerosol optical depth from satellite observations of reflected shortwave radiation. Atmos. Meas. Tech. 2018, 11, 3205-3219. [CrossRef]

7. Cooper, M.J.; Martin, R.V.; Hammer, M.S.; McLinden, C.A. An Observation-Based Correction for Aerosol Effects on Nitrogen Dioxide Column Retrievals Using the Absorbing Aerosol Index. Geophys. Res. Lett. 2019, 46, 8442-8452. [CrossRef]

8. Lee, J.H.; Yasuko, Y.; Bardara, J.T.; Philip, K.H.; Richard, L.P.; Paul, J.L.; James, C.O. Identification of Sources Contributing to Mid Atlantic Regional Aerosol. J. Air Waste Manag. Assoc. 2002, 52, 1186-1205. [CrossRef] [PubMed]

9. Hess, M.; Koepke, P.; Schult, I. Optical Properties of Aerosols and Clouds: The software package OPAC. Bull. Am. Meteorol. Soc. 1998, 79, 831-844. [CrossRef]

10. Matsui, H. Development of a global aerosol model using a two-dimensional sectional method: 1. Model design. J. Adv. Model. Earth Syst. 2017, 9, 1921-1947. [CrossRef]

11. Gasteiger, J.; Wiegner, M. MOPSMAP v1.0: A versatile tool for the modeling of aerosol optical properties. Geosci. Model Dev. 2018, 11, 2739-2762. [CrossRef]

12. Pan, X.; Ichoku, C.; Chin, M.; Bian, H.; Darmenov, A.; Colarco, P.; Ellison, L.; Kucsera, T.; da Silva, A.; Wang, J.; et al. Six global biomass burning emission dataset: Intercomparison and application in one global aerosol model. Atmos. Chem. Phys. 2020, 20, 969-994. [CrossRef]

13. Holben, B.N.; Tanré, D.; Smirnov, A.; Eck, T.F.; Slusker, I.; Abuhassan, N.; Newcomb, W.W.; Schafer, J.S.; Chatenet, B.; Lavenue, N.; et al. An emerging ground-based aerosol climatology: Aerosol optical depth from AERONET. J. Geophys. Res. 2001, 106, 12067-120971. [CrossRef]

14. Mishchenko, M.I.; Geogdzhayev, I.V.; Rossow, W.B.; Cairns, B.; Carlson, B.E.; Lacis, A.A.; Liu, L.; Travis, L.D. Long-term satellite record reveals likely recent aerosol trend. Science 2007, 315, 1543. [CrossRef]

15. Torres, O.; Bhartia, P.K.; Herman, J.R.; Sinyuk, A.; Ginoux, P.; Holben, B. A Long-Term Record of Aerosol Optical Depth from TOMS Observations and Comparison to AERONET Measurements. J. Atmos. Sci. 2002, 59, 398-413. [CrossRef]

16. Remer, L.A.; Kaufman, Y.J.; Tanré, D.; Mattoo, S.; Chu, D.A.; Martins, J.V.; Li, R.-R.; Ichoku, C.; Levy, R.C.; Kleidman, R.G.; et al. The MODIS Aerosol Algorithm, Products, and Validation. J. Atmos. Sci. 2005, 62, 947-973. [CrossRef]

17. Levy, R.C.; Munchak, L.A.; Mattoo, S.; Patadia, F.; Remer, L.A.; Holz, R.E. Towards a long-term global aerosol optical depth record: Applying a consistent aerosol retrieval algorithm to MODIS and VIIRS-observed reflectance. Atmos. Meas. Tech. 2015, 8 , 4083-4110. [CrossRef]

18. Torres, O.; Tanskanen, A.; Veihelmann, B.; Ahn, C.; Braak, R.; Bhartia, P.K.; Veefkind, P.; Levelt, P. Aerosols and surface UV products from Ozone Monitoring Instrument observations: An overview. J. Geophys. Res. 2007, 112, D24S47. [CrossRef]

19. Torres, O.; Ahn, C.; Chen, Z. Improvements to the OMI near-UV aerosol algorithm using A-train CALIOP and AIRS observations. Atmos. Meas. Tech. 2013, 6, 3257-3270. [CrossRef]

20. Dubovik, O.; Smirnov, A.; Holben, B.N.; King, M.D.; Kaufman, Y.J.; Eck, T.F.; Slutsker, L. Accuracy assessments of aerosols optical properties retrieved from AERONET sun and sky-radiance measurements. J. Geophys. Res. 2000, 105, 9791-9806. [CrossRef]

21. Dubovik, O.; Holben, B.N.; Eck, T.F.; Smirnov, A.; Kaufman, Y.J.; King, M.D.; Tanré, D.; Slutsker, I. Variability of absorption and optical properties of key aerosol types observed in worldwide location. J. Atmos. Sci. 2002, 59, 590-608. [CrossRef]

22. Jethva, H.; Torres, O.; Yoshida, Y. Accuracy Assessment of MODIS Land Aerosol Optical Thickness Algorithms using AERONET Measurements. Atm. Meas. Technol. 2019, 12, 4291-4307. [CrossRef]

23. Xu, Q.; Obradovic, Z.; Han, B.; Li, Y.; Braverman, A.; Vucetic, S. Improving aerosol retrieval accuracy by integrating AERONET, MISR, and MODIS data. In Proceedings of the 2005 7th International Conference on Information Fusion, Philadelphia, PA, USA, 25-28 July 2005; Volume 1, p. 7. [CrossRef]

24. Zhang, H.; Chen, S.; Jiang, N.; Wang, W.; Zhange, X.; Liu, J.; Zang, Z.; Wu, D.; Yuan, T.; Luo, Y.; et al. Difference in Sulfate Aerosol Radiative Forcing between the Daytime and Nighttime over East Asia Using the Weather Research and Forecasting model coupled with Chemistry (WRF-Chem) model. Atmosphere 2018, 9, 441. [CrossRef]

25. Knuteson, R.O.; Revercomb, H.E.; Best, F.A.; Ciganovich, N.C.; Dedecker, R.G.; Dirkx, T.P.; Ellington, S.C.; Feltz, W.F.; Garcia, R.K.; Howell, H.B. Atmospheric Emitted Radiance Interferometer. Part I: Instrument design. J. Atmos. Ocean. Technol. 2004, 21, 1763-1776. [CrossRef]

26. Knuteson, R.O.; Revercomb, H.E.; Best, F.A.; Ciganovich, N.C.; Dedecker, R.G.; Dirkx, T.P.; Ellington, S.C.; Feltz, W.F.; Garcia, R.K.; Howell, H.B. Atmospheric Emitted Radiance Interferometer. Part II: Instrument Performance. J. Atmos. Ocean. Technol. 2004, 21, 1777-1789. [CrossRef]

27. Turner, D.D.; Tobin, D.C.; Clough, S.A.; Brown, P.D.; Ellingson, R.G.; Mlawer, E.J.; Knuteson, R.O.; Revercomb, H.E.; Shippert, T.R.; Smith, W.K. The QME AERI LBLRTM: A closure experiment for downwelling high spectral resolution infrared radiance. J. Atmos. Sci. 2004, 61, 2657-2675. [CrossRef] 
28. Yurganov, L.; McMillan, W.; Wilson, C.; Fischer, M.; Biraud, S.; Sweeney, C. Carbon monoxide mixing ratios over Oklahoma between 2002 and 2009 retrieved from Atmospheric Emitted Radiance Interferomter spectra. Atmos. Meas. Tech. 2010, 3, $1319-1331$. [CrossRef]

29. Gero, P.J.; Turner, D.D. Long-Term Trends in Downwelling Spectral Infrared Radiance over the U.S. Southern Great Plains. J. Clim. 2011, 24, 4831-4843. [CrossRef]

30. Turner, D.D.; Löhnert, U. Information content and uncertainties in thermodynamic profiles and liquid cloud properties retrieved from the ground-based Atmospheric Emitted Radiance Interferometer (AERI). J. Appl. Meteorol. Clim. 2014, 53, 752-771. [CrossRef]

31. Turner, D.D.; Blumberg, W.G. Improvements to the AERIoe Thermodynamic Profile Retrieval Algorithm. IEEE J. Sel. Top. Appl. Earth Obs. Remote Sens. 2018, 12, 1339-1354. [CrossRef]

32. Turner, D.D. Ground-based infrared retrievals of optical depth, effective radius, and composition of airborne mineral dust above the Sahel. J. Geophys. Res. 2008, 113. [CrossRef]

33. Oh, Y.S.; Kenea, S.T.; Goo, T.Y.; Chung, K.S.; Rhee, J.S.; Ou, M.L.; Byun, Y.H.; Wennberg, P.O.; Kiel, M.; Digangi, J.P.; et al. Characteristics of greenhouse gas concentrations derived from ground-based FTS spectra at Anmyeondo, South Korea. Atmos. Meas. Tech. 2018, 11, 2361-2374. [CrossRef]

34. Lee, H.; Han, S.-O.; Ryoo, S.-B.; Lee, J.-S.; Lee, G.-W. The measurement of atmospheric $\mathrm{CO}_{2}$ at KMA GAW regional stations, its characteristics, and compositions with other East Asian sites. Atmos. Chem. Phys. 2019, 19, 2149-2163. [CrossRef]

35. Choi, J.H.; Joo, S.M.; Um, J.S. Cross-Correlation Analysis between GOSAT and $\mathrm{CO}_{2}$ Concentration observed by KGAWC Station. J. Korean Soc. Geospat. Inf. Syst. 2014, 22, 11-16. [CrossRef]

36. Wehrli, C. Calibrations of filter radiometers for determination of atmospheric optical depth. Metrologia 2000, 37, 419. [CrossRef]

37. Cuevas, E.; Romero-Campos, P.M.; Kouremeti, N.; Kazadzis, S.; García, R.D.; Barreto, A.; Guirado-Fuentes, C.; Ramos, R.; Toledano, C.; Almansa, F.; et al. Aerosol Optical Depth comparison between GAW-PFR and AERONET-Cimel radiometers from long term (2005-2015) 1 min synchronous measurements. Atmos. Meas. Tech. 2019, 12, 4309-4337. [CrossRef]

38. Kazadzis, S.; Kouremeti, N.; Diémoz, H.; Gröbner, J.; Forgan, B.W.; Campanelli, M.; Estellés, V.; Lantz, K.; Michalsky, J.; Carlund, T.; et al. Results from the 4th WMO Filter Radiomter Compariosn for aerosol optical depth measurements. Atmos. Chem. Phys. Discuss 2017, 18, 1105. [CrossRef]

39. Kazadzis, S.; Kouremeti, N.; Nyeki, S.; Gröbner, J.; Wehrli, C. The World Optical Depth Research and Calibration Center (WORCC) quality assurance and quality control of GAW-PFR AOD measurements. Geosci. Instrum. Method. Data Syst. 2018, 7, 35-53. [CrossRef]

40. Turner, D.D.; Ackerman, S.A.; Baum, B.A.; Revercomb, H.E.; Yang, P. Cloud phase determination using ground-based AERI observations at SHEBA. J. Appl. Meteorol. 2003, 42, 701-715. [CrossRef]

41. Clough, S.A.; Iacono, M.J.; Moncet, J.L. Line-by-line calculations of atmospheric fluxes and cooling rates: Application to water vapor. J. Geophysc. Res. 1992, 97, 761-785. [CrossRef]

42. Clough, S.A.; Shephard, M.W.; Mlawer, E.J.; Delamere, J.S.; Iacono, M.J.; Cady-Pereira, K.; Boukabara, S.; Brown, P.D. Atmospheric radiative transfer modeling: A summary of the AER codes. J. Q. Spectrosc. Radiat. Transf. 2005, 91, 233-244. [CrossRef]

43. Stamnes, K.; Tsay, S.-C.; Jayaweera, K. Numerically stable algorithm for discrete-ordinate-method radiative transfer in multiple scattering and emitting layered media. Appl. Opt. 1988, 27, 2502-2509. [CrossRef]

44. Stamnes, K.; Tsay, S.-C.; Wiscombe, W.; Laszlo, I. DISORT, a General-Purpose Fortran Program for Discrete-Ordinate-Method Radiatvie Transfer in Scattering and Emitting Layered Media; Documentation of Methodology, Technical Report; Department of Physics and Engineering Physics, Stevens Institute of Technology: Hoboken, NJ, USA, 2000.

45. Rothman, L.S.; Gordon, I.E. The HITRAN Molecular Database. AIP Conf. Proc. 2013, 1545, 223-231. [CrossRef]

46. Lechevallier, L.; Vasilchenko, S.; Grilli, R.; Mondelain, D.; Romanini, D.; Campargue, A. The water vapour self-continuum absorption in the infrared atmospheric windows: New laser measurements near 3.3 and $2.0 \mu \mathrm{m}$. Atmos. Meas. Tech. 2018, 11, 2159-2171. [CrossRef]

47. Wells, R.J. Rapid approximation to the Voight/Faddeeva function and its derivatives. J. Q. Spectrosc. Radiat. Transf. 1999, 62, 29-48. [CrossRef]

48. Hayasaka, T.; Satake, S.; Shimizu, A.; Sugimoto, N.; Matsui, I.; Aoki, K.; Muraji, Y. Vertical distribution and optical properties of aerosols observed over Japan during the Atmospheric Brown CloudsEast Asia Regional Experement 2005. J. Geophys. Res. Atmos. 2007, 112, D22S35. [CrossRef]

49. Deepak, A.; Gerber, H.E. (Eds.) Report of the Experts Meeting on Aerosols and Their Climatic Effects; WCP-55: Geneva, Switzerland, 1983.

50. Schuster, G.L.; Dubovik, O.; Holben, B.N. Angstrom exponent and bimodal aerosol size distributions. J. Geophys. Res. 2006, 111, D07207. [CrossRef]

51. Marsh, D.; Mills, M.; Kinnison, D.E.; Lamarque, J.-F. Climate change from 1850 to 2005 simulated in CESM1 (WACCM). J. Clim. 2013, 26, 7372-7391. [CrossRef]

52. Petty, G.W. A First Course in Atmospheric Radiation; Sondog Publishing: Madison, WI, USA, 2006.

53. Taylor, K.E. Summarizing multiple aspects of model performance in a single diagram. J. Geophys. Res. 2001, 106, 7183-7192. [CrossRef]

54. Yu, H.; Chin, M.; Winker, D.M.; Omar, A.H.; Liu, Z.; Kittaka, C.; Diehl, T. Global view of aerosol vertical distributions from CALIPSO lidar measurements and GOCART simualations: Regional and seasonal variations. J. Geophys. Res. 2010, 115, D00H30. 
55. Matthias, V.; Balis, D.; Bösenberg, J.; Eixmann, R.; Iarlori, M.; Komguem, L.; Mattis, I.; Papayannis, A.; Pappalardo, G.; Perrone, M.R.; et al. Vertical aerosol distribution over Europe: Statistical analysis of Raman lidar data from 10 European Aerosol Research Lidar Network (EARLINET) stations. J. Geophys. Res. 2004, 109, D18201. [CrossRef]

56. Turner, D.D.; Ferrare, R.A.; Brasseur, L.A. Average Aerosol Extinction and Water Vapor Profiles Over the Southern Great Plains. Geophys. Res. Lett. 2001, 28, 4441-4444. [CrossRef]

57. Noh, Y.M.; Kim, Y.J.; Choi, B.C.; Murayama, T. Aerosol lidar ratio characteristics measured by a multi-wavelength Raman lidar system at Anmeyon Island, Korea. Atmos. Res. 2007, 86, 76-87. [CrossRef]

58. Turner, D.D. Arctic mixed-phase cloud properties from AERI lidar observations: Algorithm and results from SHEBA. J. Appl. Meteorol. 2005, 44, 427-444. [CrossRef]

59. Hollweg, H.-D.; Bakan, S.; Taylor, J.P. Is the aerosol emission detectable in the thermal infrared? J. Geophys. Res. 2006,111, D15. [CrossRef] 